\title{
Mechanisms of Human intelligence - From RNA and Synapse to Broadband
}

\begin{abstract}
Simple thought has been explained by the action-potential (AP) system with its synapses. In contrast, in-depth details for "Declarative" intellectual thought have been a complete mystery because (it is argued here) its main underlying mechanism is fundamentally different. Declarative thinking depends heavily on linear coding based on digit-like elements - something which an unaided AP system could never offer.

Looking instead to psychology, Piaget (1920s) proposed basic units of action-sequences ("schèmes" whereby one could mentally construct object-concepts). There is now evidence that some ncRNA serves this verb-like actioncoding role. - (Other ncRNA demonstrably serves as adjectival/adverbial "regulators" - while the remaining $\approx 3 \%$ of RNA encodes physical structures, the traditional noun-like role). If valid, then:-
\end{abstract}

-NEW FOCUS ONTO ULTRAMICRO: - The whole Piagetian structure-coding for a concept could fit into one of the many $125 \mathrm{~nm}$ capsids ("granules"). Moreover, many more concepts (and duplicates) could fit into a cell-body. - The vast abundance of coding-sites would allow comprehensive "wasteful" rapid use of Jerneian/Darwinian selection instead of problematic "writing down" of new learnings. Estimates of memory-capacity increase vastly. - And hereditary-schèmes obviously explain inherited behaviourtraits. - Piaget's other theory about developmental stages also seems compatible.

-Quantum-constraints ensure that such micro-sites would USE OPTICAL FREQUENCY signalling. That opens the way to greatly enhanced "Gigabit" rates, and optical-interference tricks.

-MYELIN gets the EXTRA ROLE OF OPTIC-CABLE.

So nerve-fibres become seen as simultaneous paths for two different types of signal (also demonstrated by Sun-et-al, 2010), with AP still dominant in some roles, but subservient to "UPE" optical signals elsewhere.

-LOCATING MEMORIES? Choosing the right address means selecting some sort of "phone-number or numbered plug-socket." That is best provided as an "address-label" sequence on the transmitted version of the schème-coding in which case, actual destination-location may be less important.

•"Moving-house" tO CORTICAL LONG-TERM MEMORY. The memory-move must preserve existing (i) memorystructure, and (ii) links to distant static archives.

This "impossible" task would seem feasible if memories are actually held within individual cells (as above). There is indeed lifelong flow of such neurons in some mammals; but these flows seem to cease in adulthood for humans and dolphins! So the search continues.

\author{
(C) Robert R. Traill (2019) \\ 29 Charlotte Street, Blackburn South, 3130, \\ Victoria, Australia \\ rrtraill4\{at\}bigpond.com
}

\section{Contents}

1. Seeking new brain-principles...................................................

2. The Suggested Photon-Mode (added to AP).

$2 \cdot 1$ New Evidence for this Double-Effect.

$2 \cdot 2$ Grades of Radiation-Signal . 3

Memory, 1D-Code, and Intelligence ..........................................5

3.1 Some important ideas from Kant...................................... 5

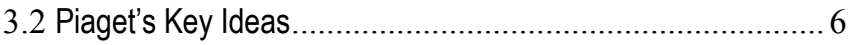

4. Material Bases for These Constructs.........................................6

4.1 Miniaturization and a Need for Redundancy. ........................ 6

4.2 Some Other Guiding Principles in this Bio-Context................ 6

4.3 Substructure of a Piagetian schème - The Taton? ............ 7

4.4 A Text-like 1D Structure for this Taton? ............................... 7

4.5 Functional Organization within such 1D Tatons? ................... 7

4.6 A Material Embodiment for the Taton? ................................. 8

4.7 How does New Learning get onto Tatons? ........................ 8

5. Linking such Candidate-parts .................................................. 8

5.1 Assembling Taton Units into Schèmes and beyond.............. 8

5.2 Cells as Possible Schéma-Files ......................................... 11

5.3 Possible Role for virus-sized containers.............................. 11

5.4 Could these items fit in? — "Tape-measure" evidence.......... 12

5.5 Conducting a link between distant sites?............................ 12

5.6 Attention-"centre" and the flow of concepts ....................... 13

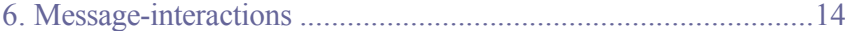

6.1 Message "programs"...................................................... 14

6.2 Uniting sometimes-remote schemoids ............................. 15

6.3 Activating remote schemoids ........................................ 15

6.4 Finding little-used schémata: Dim memories ..................... 16

6.5 Fading schémata in the hippocampus ............................. 16

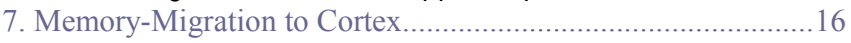

7.1 Patient-HM with no hippocampus nor "wkM" ........................ 16

7.2 Properties of the imM (Immediate Memory)? ........................ 17

7.3 From Hippocampal wkM to Cortical LTM?........................ 17

7.3.3 Any Evidence for such a Schéma-flow?.............. 18

7.3.4 Observed flow of Neurons into the Cortex.......... 18

7.3.5 Migration-failure in Primates and Dolphins? ...... 18

7.3.6 Interpretation and Possible-Solutions? ................ 18

7.4 Immediate-Memory to hippocampal wkM? ....................... 19

References......................................................................... 19

Keywords: Piaget, ncRNA, schéma, coaxial, myelin, hippocampus, Kant, neurogenesis, UPE, infrared, Long-Term-Memory, epistemology, biooptics, Scientific-Method, Brain-mechanism, Jerne, neuron-migration 
For some time there has been an impasse on the details of mind/brain activity:

"... we seldom know what operation each [brain-]region is performing ... and in some instances we do not have even the faintest idea of what is going on." - Crick (1979) ${ }^{\mathbf{1 3}}$

Forty years later we still hear similar frustration from: Fuster \& Bressler(2012) ${ }^{\mathbf{2 0}}$, Gallistel \& Balsam $(2014)^{22}$, Koch \& Marcus $(2014)^{40}$, Trettenbrein (2016) ${ }^{95}$, Horgan $(2016)^{32}$, Brette (2017) ${ }^{6}$; - and even from Mattick's team ${ }^{49,17}$ although their ncRNA comments offer some hope as we shall see.

Some have gone further and doubted the legitimacy of such reductionist attempts altogether ${ }^{3,75}$. But note that this all assumes that the all-powerful underlying mechanism entails synapses and action-potentials (APs) as the only significant material bases - and it is convenient to refer to this setup as the "AP" or "[A]" system.

Meanwhile, even alternative thoughts about "Computer intelligence" can be misleading.

E.g. the computer does not have to attend to most of those "boring chores" like maintenance that beset a real-life system. So maybe it is time for a different (but bio-compatible) approach:

\section{Seeking new brain-principles}

Neuroscience has advanced notably in such areas as connectivity and related methodology (and details of simple "nondeclarative" nervous systems like that of Aplysia ${ }^{79}$ ), but it has offered almost nothing coherent about detailed sub-mechanisms which might underlie human declarative thought. ${ }^{75}$

Neurophysiologists seem to go as far as they can, given the apparent impossibility of studying any Thought- $X$ at its most basic coding level - i.e. impossible using microscopes or known imaging techniques, especially as it has not been clear just what to look for at that level. Thus their progress has mostly been somewhat more macro in its scope (e.g. Squire \& Kandel $^{79}$, Chs.4-6) - which clearly has its uses, but leaves us with the proverbial "Black Boxes" whose overt behaviour-patterns (and some chemistry) become known, but leave us largely ignorant about what basic systematic internal mechanisms cause that behaviour. And that seems to accord with the complaints from Professor Rose ${ }^{75}$ and others.

Such an impasse might thus induce us to search elsewhere for an alternative approach. E.g. change our focus from trying to observe direct causes, and instead (i) note their detailed results, (ii) gather comprehensive clues about possibilities for their mechanism-construction, and (iii) seek to reverseengineer such bio-feasible mechanisms to explain those Advanced Thinking-Behaviour patterns.

However reverse-engineering can only work well if the key putative components are reasonably welldefined - having a manageable number of degreesof-freedom. (E.g. Mendel's restrictive gene-concept allowed genetics to develop). The trouble may be that our observations are not obviously reducible to those essential "well-defined" sub-components. And yet...

The potential breakthrough came in the 1920s with Piaget's concept of the "schème" - a hypothetical basic element of action (or its material encoding). Individually, each such schème was potentially well-defined (perhaps an RNA-like molecule), even if we could not measure its "welldefined" properties directly. More details below, but the point here is that this construct did-and-does allow for plausible model building - with Mendel, Mendeleev, Bohr (and fictional detectives) as forerunners in that constructive art.

As long as such basic elements remain credible, or are replaced by other similar elements, then there is indeed a reasonable chance of making progress through this backdoor route. However experience has shown that the task is likely to call upon evidence from a considerable number of interdisciplinary sources - and a concerted effort to integrate their various findings.

Here such needed disciplines have included: - Developmental-Psychology, E Epistemology (Knowledge-Theory), $\bullet$ General-Biology — these being Piaget's own three specialities.

Then Physics (especially optics, cable-theory, and the history of their developments), $\bullet$ OrthodoxNeurophysiology (especially synapses), $\bullet$ RNA and related issues; - plus $\bullet$ Neuro-anatomy, and - Telecommunications-theory.

Studied in isolation, many of these specialities have made their own vain attempts at the mind/brain problem, but the prospects improve if their insights are instead applied collectively. Here, these contributions will largely be introduced individually, but that discussion will make better sense if we first "cheat" - and look at the "answers at the back of the book" to see where the collective argument is going. So here is a preview outline of the earlier conclusions - some of them surprising:

(1) That there are TWO simultaneous modes of fast transmission in myelinated nerve-fibres; the extra one involving low-intensity photon-beams of 
infra-red (IR) \&/or some rainbow-colours - using myelin as a coaxial cable; (first discussed as a biological high-frequency-circuit possibility in Part $\mathrm{B}$ of ${ }^{88}$, and and in ${ }^{89}$.)

(2) This photon-mode (with its optical effects) probably predominates within the inner parts of the brain, while peripheral nerves are likely to mainly conform to orthodox AP-accounts.

(3) Short-term memory is composed and stored as ensembles of language-like code using ncRNA. ${ }^{\mathrm{A}}$

(4) The existing idea that Long-term memory is probably held as DNA is thus made more plausible.

(5) More about ncRNA: About $98 \%$ of human RNA is NOT involved in protein-production. ${ }^{47}$ Some of this "ncRNA" is explained as having a regulatory role, but much of it has been left unaccounted for. Significantly though, about $40 \%$ (of "Long" ncRNA alone) are found only in the brain. ${ }^{26,7}$

The conclusion here is that much of this remainder probably serves as modifiable basic action codes, either for random (Darwinian) action-trials, or as important inherited behavioural traits, (mannerisms which are thereby easily explained!).

(6) Such coding intercommunicates using the photon-mode - at a vastly greater "Gigabit rate" than action-potentials (AP) could ever achieve.

(7) Likewise the potential storage capacity (and systematic order) of the brain increases by several orders of magnitude - allowing the use of "wasteful" mass Darwinian trial-and-error strategies in learning (a strategy identified clinically by Piaget, and noted separately by Jerne in 1955 regarding immunological knowledge-acquisition; ${ }^{34,8,9,35}$ ).

(8) Meanwhile synapses and APs clearly still have a number of roles - perhaps tentatively best summarised as often relating more to $2 \mathrm{D}$ and $3 \mathrm{D}$ phenomena, including - path-optimisation and - pattern-recognition, - primitive "non-declarative" mechanisms as in Aplysia; - and obviously • direct interfacing with the outside 3D-world via the peripheral sensory and motor nerves.

(Such 2D/3D tasks contrast with the more 1D nature for much of logical thought, and its supposed basic encodings. - Moreover our full processing of visual images seems to require both approaches, usually simultaneously: The more active 1D-based tactics of Piaget/Pylyshyn, plus the more passiveand-holist 2D/3D account of Kosslyn/Bókkon), ${ }^{94}$ and see footnote "G" on page 6 below.

(9) Whatever the basic coding method (RNA or synapses, or any other less-than-perfect units),

\footnotetext{
A ncRNA is "Non-Coding" for protein production, but that leaves it free to code for other tasks. See Mattick $(2001)^{44} \mathrm{ff}$.
}

effective memory will usually need to be held collectively by a coordinated "choir" of such basic units (to avoid any untoward individual fluctuations ${ }^{\mathbf{B}}$ ). - And note that it would be much easier to achieve any such sophisticated choircoordination using RNA units than by attempting it with Hebbian ${ }^{29}$ synapses within the AP system.

$\S 6$ will then describe attempts to apply these apparent insights in explanations of mechanisms for storage and retrieval, plus $(\S 7)$ the conversions of memory, thus:- immediate memory (imM) $\rightarrow$ working memory (wkM), and then $\rightarrow$ Long-Term (LTM).

Meanwhile:-

\section{The Suggested Photon-Mode (added to AP)}

The idea comes historically from two independent sources:

- A logical consequence of Piaget's "schème" concept and the RNA-interpretation of it, introduced above and discussed below; and:

- A consequence of the work on "Ultra-weak Photon Emissions" (UPE)s ${ }^{10,11,92(\$ \#) ~}$ started by Gurwitsch in $1924^{24,25}$ - But note that such UPEradiation is a general phenomenon found in all living matter, ${ }^{96}$ so its mere presence need not necessarily relate to neural-transmission as such. Or, to put it another way: Might we expect that UPE communication evolved first, with nervous systems later arising as an "add-on" facilitation? After all, plants figure significantly in the history of UPE studies - and APs have not always had their clearcut millisecond "spike", which had to evolve from less effective chain reactions. ${ }^{5,88(\mathrm{ch} . \mathrm{B} 5)}$.

Anyhow it was this latter context which inspired the immediately-following important investigation:-

\subsection{New Evidence for this Double-Effect}

Sun et al (2010) ${ }^{\mathbf{8 0}}$ applied optical stimulation at one end of rat spinal nerves, and measured autographic optical responses ${ }^{\mathrm{C}}$ at the far end. Such signals seem to have been normally transmitted by both the traditional APs and by photons.

When both were suppressed, the signal stopped; but transmission continued when only one of these two

\footnotetext{
B "Choir" is perhaps also needed to produce an approximatelaser effect, through well-coordinated photon-emissions.

C Seen via the well-known photographers' use of photon-detection by the effect on silver nitrate $\left(\mathrm{AgNO}_{3}\right)$ in close contact. (c) R.R.Traill, 2019
} 
modes was suppressed ${ }^{\mathbf{D}}$ - which implies that the two modes are alternatives at least within spinal nerves. - A sort of "Plan B" arrangement.

That does indeed seem to justify the key claim for a two-fold mechanism, and that is encouraging for the UPE case; but we will see that it overlooks some features that the Piagetian/RNA interpretation would require for a more thorough picture:

Firstly the study did not tackle deep-brain communication where photon transmission is a crucial part of the argument.

(Indeed, as one might expect, the Sun-et-al experiment focussed only on nerves outside the brain-proper. Hence its success showed only that photon transmission was feasible in some nerves, which is helpful; but even if it had failed to find photon-effects in this PNS context, there would still be room for suspecting the effect deep in the brain - consistent with the account offered here).

Secondly it made no mention of cable theory (see below) which might have carried the input signal by uninterrupted transmission, and deposited it at the detection end (intact, apart from any transverse effects if the nerve-fibre cable were too wide, see footnote "U" below). Instead they postulated a chain of photochemical reactions between quasi-neighbouring cells, with successive regeneration of new photons.

Thirdly it seems almost incidental here that their initial stimulation was optical. The use of six different input wavelengths/colours evidently made no significant difference, so maybe other types of stimulus could have had the same effect, especially if any sort of relay is involved initially. However that does not upset their case, provided that the EM (electromagnetic) part of the signal does promptly become transmitted photons.

As a further comment: If this had been a fibre from the inner brain we might be left wondering whether the photon-radiation might be carrying sophisticated messages (not just present-vs-absent) - in the way that such radio-like transmissions are theoretically able to do. With that in mind, let us start with some new distinctions:-

\subsection{Grades of Radiation-Signal}

Déjà vue! - During the 1800s, ideas about the electro-magnetic transmission of messages went through a whole series of increasingly sophisticated steps; and it now looks as though our claimed-

\footnotetext{
D They used procaine, to stop AP-transmission \&/or 2-deoxy-Dglucose against the metabolism assumed to be behind photon regeneration.
}

understanding of brain signalling could be passing through similar stages (but at a vastly smaller sizescale) - rather like the following sequence:

(a) Simple on/off switches-or-alarms, perhaps responding to thresholds. Cf. AP and Hebb (1949) ${ }^{\mathbf{2 9}}$

(b) Loose bundles of such wires, e.g. each lighting-up a letter of the alphabet in sequence. Useful but cumbersome. - Or tight well-organised bundles conveying 2D image-pixels; e.g. Retina-toOccipital-Lobe, (though with some processing en route).

(c) Morse code on single telegraph-lines. No clear brain equivalent despite some focussed searches.

(d) Thick cladding to cope with under-water capacitance for trans-Atlantic cables at low transmission rates. Wm. Thomson (Lord Kelvin) ${ }^{83}-$ Myelin maybe evolved initially for similar reasons, though with AP beneficial-complications?

(e) Improved design of cable geometry and components to cope with HIGH FREQUENCY and much greater throughput (Heaviside, 1894) ${ }^{28}$. Vertebrates acquire a new myelin-forming protein (PLP instead of $\mathrm{P}_{0}$ ) which produces more compact-and-tidy myelin ${ }^{39}$ - presumably producing significantly greater throughput and precision for electromagnetic signals (whereas such tidy geometry would offer very little new benefit to the accompanying APs).

(f) The incidental invention of radio (Hertz), and its commercialisation (Marconi) - as an extension of high-frequency cable transmission - allowing wire-free transmission, and hence vastly greater flexibility.

Likewise, possible leakage of any highfrequency neural signals as UPEs - either by accident, or as short-range excursions from myelin: This could allow signals some freedom at the far ends of their myelin paths if the "terrain" were suitable: (as if "walking home after getting off the bus").

(g) Crude telephony-attempts to transcend morse-telegraphy, though with voice-distortion problems. Any bio-equivalent? No clear answer, though some speculation that some bio-systems might actually depend on such distortion for repeatable "format change"! See $\S C 6.7$ of ${ }^{\mathbf{8 8}}$, especially fig.C6.7/2a added in 2006.

(h) Use of modulated carrier-waves largely fixes voice-and-picture distortion, and enables channelseparation in increasingly sophisticated ways. No information yet on any such bio-system, but it would be prudent to watch for it. 
(i) Such quasi-stable radiation enables the use of optical tricks like standing-wave patterns, GPS navigation, etc. - and it seems likely that our mysterious ability to assimilate binocular vision (with both Piaget/Pylyshyn and Kosslyn/Bókkon interpretations simultaneously: action-based plus pixel-based), and binaural hearing, may well depend on such tricks. But perhaps time will tell.

(j) Likewise, WiFi is a way of handling messagetransmission when the intervening optical-paths are in a state of flux, and otherwise-likely to interfere with each other. Such an ability could be very useful within the brain, as we shall see in $§ 5.5$.

Note that most of these special features would not be available to any pure AP-system.

That completes the preview of signaltransmission alternatives to AP, (items (1) and (2) in $\S 1$ ). So now let us turn to RNA/DNA as memorystorage alternatives to any synaptic arrangements items (3)-(7) in $\S 1$.

\section{Memory, 1D-Code, and Intelligence}

How do we handle thoughts? That is primarily a matter of epistemology (the study of knowledge: how it is acquired, stored and retrieved, in the brain or elsewhere). ${ }^{\mathbf{E}}$

Here the two most relevant epistemologists are arguably Kant (1724-1804) and Piaget (1896-1980). Unfortunately neither were particularly lucid in their prolific writings, and there are translation-and-paraphrase problems. But they still deserve close attention, emphasizing what micro-abilities a brain-like system needs, rather than what seems most salient.

\subsection{Some important ideas from Kant}

(K1) the Schéma - $\sigma \chi \eta \dot{\mu \alpha}$ : form/shape, (plural "schémata" or "schemas") — an idealised ${ }^{\mathrm{F}}$ general-

\footnotetext{
E I here take "knowledge" to mean any encoding of what purports to represent some part of reality. It need not be true, and it certainly need not be conscious, though it can be either or both

${ }^{\mathrm{F}}$ How could a practical system (like the brain) cope with this seemingly intangible idealized schéma-entity? One solution could be to compromise slightly and accumulate a large-andvaried collection of relevant images-or-templates (if there is enough storage space), and use powers of interpolation etc. to assemble a generalized impression - somewhat like a successive-approximation method in maths. (Not strictly correct, but like $\pi$-evaluations, usually amenable to asymptotic improvement as far as needed.) That could actually fit quite conveniently with the apparent simultaneous need for a "choir" of similar codings - (as noted in $\S 1$ above, and $\S 4.1$ below).

- Note too some similarity to our successful interpolated approximation between frames of a conventional movie-film, with its 24 frames per second.
}

mental representation (probably inspired by Plato) e.g. of a triangle, or a dog etc.: ..."always a mere product of the imagination" $\left\{\mathrm{Kant}^{37} \mathrm{p} 118\right.$, \& see (K3) below \}, "but it mustn't be confused with an image" (Kant \& Bennett; p.92) ${ }^{38}$; and "without being restricted to any one particular shape." (ibid.)

Piaget later developed this idea significantly, as we shall see. (Indeed any such subsequent trend toward physiological interpretation should surely be taken seriously, at least initially; and whether Piagetian or not).

(K2) Synthetic a-priori. Is all our knowledge learnt from scratch? (If so, then how do we know how to learn!?) It seems we must have some startup knowledge - some inherited-or-mystical "a priori" knowledge which was difficult to explain, especially before modern evolutionary and epistemological theory. Kant fudged a bit here, calling it "synthetic a priori"; supposedly comprising our basic axiomatic "categories" of space and time dimensions etc. Later improved by Piaget.

(K3) Action first - before learning. Inspired by some seemingly back-to-front Copernican logic, Kant made the important proposal that suppositions about the world originate haphazardly in the brain, and are then tested by the reality outside (rather than recorded by passive absorption); (p14). ${ }^{37}$ That can allow the solving of "intractable problems" by massed trial-and-error (when there is nothing better to guide us).

The idea has its limits, but it can now be seen as the ultimate default starting strategy of all epistemological systems, viz. The $\bullet$ Brain, the $\bullet$ Immune system, $\bullet$ Evolution of DNA across the generations, and the $\bullet$ Society-as-such (as partly embodied in its scientific establishment). ${ }^{91(\$ 8 f), 90(c h .4)}$. To partly transcend this robust-but-tedious Kantian(Darwinian) process requires an intelligencemechanism (not necessarily conscious), and of course that is what our present study seeks to explicate. Which leads us to:

(K4) Transcendental Schémata - with no direct reference to outside objects or events, but instead referencing lower-level schémata (which are outward-looking), thus offering some extra organization $\left(\mathrm{Kant}^{37}, \mathrm{p} 65\right)$. - Though I may be reading more into his account than is warranted. Anyhow that seems to offer a basis for Piaget's wellknown "Stages" theory which does seek to explain intelligence in terms of control hierarchy. See below, (plus figs (i)-(iii) on p.14 of ${ }^{86}$ ). 


\subsection{Piaget's Key Ideas}

Piaget seldom mentions Kant explicitly, but the connection is obvious (if only from some titles of his earlier works, e.g. on space ${ }^{68}$, time ${ }^{67}$ and causality ${ }^{66}$ ). His main concepts are:

(JP1a) In about 1946 he made a significant distinction between "schéma" (e.g. for a whole conceptual object or event), and "schème" for elementary constituent actions underlying a schéma concept - a distinction not always observed by translators, nor sometimes even by Piaget himself! ${ }^{91(p .22)}$

(JP1b) Importantly he saw a schème as being an action and not an object-like entity as most people would assume.

I take his "action" to include "encoding for that action" though he might not have agreed. Anyhow actions in scanning objects like "Teddy," (by hand $\& /$ or vision etc.) would seem easier to encode meaningfully from scratch, rather than coping with the less analyseable "photographic-pixellated" object itself. ${ }^{\mathbf{G}}$ More-so if the child has to find ready-made a priori schèmes to build with — in accord with (K3) above, and (JP3) below.

(JP2) Piaget showed experimentally that Kant was wrong about his "aesthetic" schémata of space and time (etc.) being inborn. They are actually developed during infancy. ${ }^{66,67,68}$ Nevertheless Kant was still apparently right in principle, in that the more fundamental-and-micro constituent items basic schèmes - were likely to be available instead, to serve as the "axiomatic" synthetic a-priori elements.

(JP3) Action first. Yes, Piaget certainly agreed.

(JP4) Not just one transcendental layer, but an actual control-hierarchy developed during the growth to adult-level mental-ability. This is the basis for Piaget's best-known theory, about the stages of development: - from Sensori-motor, to Pre-operational, to Concrete operations, to Formal operations; (e.g. Phillips, 1969). ${ }^{65}$ Each level evidently has its own rank of schémata monitoring the next-lower level. (It can be convenient instead to call them " $M^{0} L, M^{1} L, M^{2} L, M^{3} L$," respectively; where " $M^{1} L "=M L=$ Meta-Level" etc.).

Note that Ashby ${ }^{2}$ designed a mechanical model on similar principles, though that was a quite independent elaboration of a thermostat-control type

\footnotetext{
G This line-tracing vs pixel image is an important DualPlus distinction (see $\S 4.2$ (a) below); - here between the "conflicting" views of Pylyshyn-and-Piaget on the one hand and Kosslyn on the other, as discussed in ${ }^{94}$ which argues that both mechanisms are probably necessary (and in cooperation).
}

of device. The two models have been compared in some detail. ${ }^{88(\text { ch.Cl-C5) }}$

\section{Material Bases for These Constructs}

\subsection{Miniaturization and a Need for Redundancy.}

Note Piaget's scale-shift down from schéma to schème. This was a step toward smaller, more mechanically describable entities. That was arguably a step in the right direction (which worked very well in chemistry, leading to the Bohr/Schrödinger atom and an understanding of its properties. ${ }^{64}$ ).

Meanwhile though, in modelling the mind/brain we need to ensure that decisions and behaviour are not usually dependent on any such single microstructure - because that would often lead to very odd-and-capricious changes of behaviour whenever the single encoding was revised-ordamaged. Accordingly it seems necessary to postulate a normal largish population of "redundant" closely similar encodings, forming a sort of choir (which must learn to act in unison, or at least in synchrony) - as introduced in $\S 1$ above.

Also, that choir-need should apply to any system of not-quite-reliable components, viz.: (i) any new RNA-based system ("[R]"); — or (ii) any Hebbian ${ }^{29}$ AP-system $I F$ we were to still believe in it having a role in this intellectualisation task (though it is difficult to imagine how such a choir-organisation could be managed for such AP-type systems).

Meanwhile (either way) that redundancy helps explain the role of practice and training leading to skilled behaviours - building up the membership and coordination of such "choirs."

\subsection{Some Other Guiding Principles in this Bio-Context}

Although not rigid laws, there are some practical guiding principles which seem (i) to be reasonable items of common-sense (even obvious in retrospect); yet (ii) easily overlooked. And often (iii) of practical assistance:

(a) DualPlus. Biological problems often have more than one feasible solution, and these can often all be true - even simultaneously in the same species, (or at least such an alternative might be found in some other life form). E.g.(1): Various respiration modes; (2) The postulated use of myelin for two different signal-modes ( $\$ 2$ above); (3) The apparent double-process of vision processing within mammals [Footnote G] plus other forms in insects etc. 
(b) AnomalyCue. "Troublesome" anomalies can actually be helpful, especially if they are clear-cut forcing us to re-examine our assumptions and look further (maybe radically, and perhaps in helpfully specific directions - and not usually to instant scrapping of the whole idea, as radical Popperians might demand!). E.g. (here) the apparent impossibility of explaining intelligence by the AP/Synaptic-system, alone-and-unaided.

(c) HidMicro. Solutions might be found by envisaging (and later maybe finding) causes beyond our current powers of adequate observation - often because they are too small, or too embedded.

\subsection{Substructure of a Piagetian schème - The Taton?}

To Piaget, the schème was itself the basic (abstract) substructure. But if we are seeking a material basis, we have just seen that this practical schème is likely to be a choir of near-clones. So, whatever the basic indivisible micro-action coding elements might be, it is helpful to use a special name for them. Hence "taton" (2008) taken from the German word "Tat" ("deed, action") 1 — less cumbersome than "the simplest type of isolated schème." - (And not to be confused with « tâton »!)

\subsection{A Text-like 1D Structure for this Taton?}

"Message-code" usually implies one-

dimensional (1D) patterns or lists, especially if we need an ability to operate in real-time, as in speech - so 1D status will be assumed here for speech-like messages.

Lock-and-key models seem different, with 2D or 3D codes - as in the protein-shapes applying in bacteriology - and in IMMUNOLOGY. But there too, $1 D$ is used, even though it is then translated into solid 3D "keys," each ready for any lock which happens to match it. Now, as noted above in $\S 3.1(\mathrm{~K} 3)$, (and in 70, 90(ch.4), 91(Table-S; p.31.), 93(\$10) , the four significant knowledgegathering (epistemological) systems appear to be:

(1) Mind/Brain/Intelligence (our focus here);

(2) Society-as-such, including Science;

(3) Evolution-with-DNA; (4) Immunology.

Of these, (2)-(4) clearly depend heavily on 1D coding; so by analogy alone it seems likely that (1) does too (though other reasons are being offered here as well). And such internal 1D "Language of Thought" has also long been favoured by the philosopher J.Fodor $(1975,2008)^{\mathbf{1 8}}$.

\subsection{Functional Organization within such 1D Tatons?}

It seems fairly obvious to take cues from machine-level computer programming and postulate a 1D string consisting of (1) a LABEL-sequence, filtering out all but the properly addressed signals; then (2) a PROGRAM-sequence — as in ${ }^{86(p .10, f i g(i v))}$ thus ( with "Label" meaning "identifier," "address," or "phone-number"):

\section{Summary: $\quad\left[\begin{array}{l|c}\hline \text { Label } & \text { Program }\end{array}\right]-[\overline{\text { Tag }}]$}

There was also (3) the extra "Optional AFFECT-TAG (Not necessarily situated in this position)" seen as governing the longevity-or-reproducibility of that taton. $^{86}$ - That may be of future interest, but here it is merely mentioned in passing.

Instead, a more helpful extra could be "(11/2)" placed between (1) and (2) — as a set of on/off switches controlled by mood-hormones (endocrine or "neuro-transmitter") intruding from the side, and hence that particular program section would only be active during the relevant mood's presence-(orabsence). That could aid our explanation of emotions. And trauma (or drugs etc.) might radically re-set these switches or their thresholds.

Thus: [Label | Switches | Program ]

Such switches offer a form of censorship, or at least a directive about immediate priorities; - and their suggested role also seems consistent with Freud's unconscious repression, (and conscious suppression) of uncomfortable communications.

Meanwhile note the formal similarity to various formats and protocols used in practical internet communication. These specifications are "RFCs" ("Requests for Comment." Some have been implemented for a while - until a better format arose. E.g. RFC 822 (structure) and RFC 821 (its protocol) - both now obsolete but their documentation is easily available. Such early historical formats are perhaps closer analogues to tatons, though later ones may offer helpful extra ideas. (One interesting feature is the need for a return address).

Anyhow such analogical notions will turn out to be important in $\S 6$ below. (And note that this is a case of potentially useful hints between epistemological domains). 


\subsection{A Material Embodiment for the Taton?}

What bodily items offer text-like structure, with well-defined "syllables"? The only candidates seem to be DNA, RNA, PNA, and protein. PNA is too rare, protein is too lumpy (or else unhelpfully repetitious). DNA is a possibility, though perhaps too stable except for long-term memory (LTM). RNA seemed the best candidate by $1975^{86 \text { (ch.1, p.10) }}$ encouraged by news of Hydén's earlier findings of RNA-changes during learning (e.g. ${ }^{33}$ ).

The doctrine until 2000 was that most RNA was mRNA coding for protein, but we have just seen that protein seems unsuitable for embodying tatons. But then, what if some RNA were free from traditional mRNA tasks, and instead available for message-coding in their own right?

Astoundingly this availability turned out to be at least $97 \%$ true 26 years later.

(Significantly, this extreme percentage refers specifically to humans. Bacterial data misled us.)

However there are now also established claims that many such available ncRNAs (non proteincoding) serve as "regulators" (e.g. Mattick 2018) ${ }^{47}$, which implies competition between two different $n c R N A$ role-types. Or, to look at it another way physiologically:- Maybe our thought processes are just one type of "regulator" amongst the others!

\subsection{How does New Learning get onto Tatons?}

Could this new bio-learning be like taperecording, (occurring automatically without interpretation)? Not likely at the Sensorimotor $\left(\mathrm{M}^{0} \mathrm{~L}\right)$ stage: - That would require the prior evolution of purpose-built recording devices and ways to maintain them.

Maybe at $\mathrm{M}^{\text {high }} \mathrm{L}$ stages though:- After all, we do have human-designed (external) recording machines thanks to $\mathrm{M}^{3} \mathrm{~L}$ intelligent thinking, but it is not at all clear whether such $\mathrm{M}^{3} \mathrm{~L}$ schémata could work the same wonders within the brain itself.

In general though, such learning is likely to be heavily reliant on the same Jerneian-DarwinianKantian trick used in immunology (as noted earlier in $\S 1 .(7)$ and $\S 3.1(\mathrm{~K} 3))$ :- - viz. Rapidly vet a huge number of assorted candidates, and select any which seem (by chance) to already encode the right message.

The method is only feasible if you have a large number of expendable candidates - and that is made possible within the (ultra-micro) RNA-coded system discussed here; where high-speed is also achievable.
The notion of the expendable random candidate corresponds to the term "objet trouvé" (page 24 $\left.\mathrm{of}^{90}\right)$, borrowed from the art-theory of Marcel Duchamp. It also sheds new light on the concern that much of our RNA may still be "junk" (Palazzo \& Lee, 2015) ${ }^{60}$ — whereas such "junk" may be a necessary stock of raw-material (like never-used antibodies in the blood), which is otherwise harmless apart from the logistics behind its upkeep.

In any case, how can a mere observer (as yet) tell which of the brain's ncRNA molecules is "potentially useful junk" and which is an alreadyordained taton (selected or inherited)?

Then again, the ncRNAs surveyed ${ }^{60}$ seem to have been all-or-mostly from non-brain tissue in which case any "unsuccessful candidates" will have been "waiting in the wrong queue" and hence really will be junk presumably!

\section{Linking such Candidate-parts}

\subsection{Assembling Taton Units into Schèmes and beyond}

A strip-cartoon once depicted an office-scenario: VISITOR: So, what filing system do you use here? ClERK: The Biblical System

VISITOR: Oh! — What's that?

CLERK: "Seek and ye shall find!"

For that under-organised office, it is implied that the only way to find an item is through recognising it by its intrinsic properties (not its category or provenance) as one arbitrarily scans the relevant domain - perhaps the proverbial "needle in a haystack". Technically this is an "INTENSIVE DEFINITION" for that item, or for the class of all such "needles". Such a formulation clearly has primitive validity and a (limited) practical usefulness, especially if the items are identified by clear essential properties (properties which endure even if the item is otherwise "lost" in amongst other randomly distributed items, or left unfiled, or even wrongly filed).

In the mind/brain context, let us take this as "specification type-\{0\}". And note that it does also have other bio-application, especially in immunology with a particular antibody searching just in case its matching antigen should happen to invade the system (in which case it will promote protective measures). - In that example, identification is said to occur by a "lock-\&-key" recognition-mechanism.

Alternatively we can use an EXTENSIVE DEFINITION for all those items captured into a group in some specified way (presumably to save us the inconvenience of repeated haystack-searching! - 
though note that some semi-hidden use of this initial-identification $\{0\}^{\mathrm{H}}$ will presumably still be needed):-

$\{1\}$ "Glued" — direct "contact" (thermodynamically stable as in chemical compounds, via weak bonds). But let us distinguish between $\{\mathbf{1} \mathbf{a}\}$ those joined by side-additions (perhaps via chemical side-chains, and maybe due to editing); e.g. fig. 1 if its links were material rather than "virtual" — and $\{\mathbf{1 b}\}$ those joined end-to-end (perhaps as read directly from DNA).

In accord with DualPlus, both seem likely although the end-to-end version $\{1 \mathrm{~b}\}$ now seems rather attractive because (i) that $1 \mathrm{D}$ organisationmode seems to suit DNA and RNA, even when the external transactions seem somewhat remote ${ }^{\mathrm{I}}$; and (ii) most of the available ncRNA is long (LncRNA, >200bp). ${ }^{7}$ Note that such a linked ABCD could be essentially the same as CBDA and yet be taken as different when observed in the laboratory; so identification of substrings should be helpful (as with introns and exons).

$\{2 a\}$ Tethered physically by a rope-like leash (a variation of $\{1 \mathrm{a}\}$ ).

$\{2 \mathbf{b}\}$ Quasi-tethered by a dedicated telegraph or "audiofrequency telephone-line, (pre-1950)" or its analogue: a traditional nerve linkage, usually tacitly assumed to be signalling somehow by APbased Morse-like codes. (Such discrete coding has never been found and now seems improbable; but instead, any signal seems simply to be in the statistical rate of AP-spikes).

\{2c\} Quasi-tethered by a dedicated local "opticalfrequency cable" (myelinated), or an equivalent commercial TV-or-microwave cable. HowEVER such frequencies can (in the right circumstances) break free from the cable and be broadcast-or-elsebeamed (as with Hertz's discovery of radio in the

\footnotetext{
${ }^{\mathrm{H}}$ These various " $\{\ldots\}$ " distinctions need not be absolute, but it will perhaps suffice to see each as the main applicable tactic within its given context.

I This idea of remoteness when crucial entities are confined to a single one dimensional string has obvious application, both to intron/exon matters, and to these supposed end-to-end joinedup tatons of case $\{1 \mathrm{~b}\}$. It also matches the not-too-serious discussion of hypothetical 2D and 1D beings in the book "Flatland" — which (e.g.) raises the question of two 1D beings seeking to mate, but with no prospect of any physical contact. As one step towards feasibility, such a system would presumably need a very efficient message-coding system to allow highly selective virtual contact - and that might have some bearing on the present discussion (which at least allows messages to take short-cuts through the 3D medium - and access to other $1 \mathrm{D}$ entities).
}

late 1880s), which takes us instead to the less-local $\{5\}$ below, with call-sign-variety the limiting factor. \{3\} Held captive within some boundary-or-box (notably within a cell or vesicle). See $\S(\mathbf{5 . 2})$, below.

$\{4\}$ Highlighted by focussed beams (by centrally controlled simultaneous "searchlight"-beams of UPEs or any other radiation capable of sufficient focus and sufficient ability to penetrate the prevailing medium predictably) - an alternative to using dedicated pathways as in $\{2\}$.

IR-frequencies would be poor candidates on oneor-both counts. $\mathrm{UV}_{\mathrm{A}}$ (or nearby visible-light quanta) seem more promising, especially as it seems plausible that long mitochondria (recently identified) could be acting as lasers (using an optical trick to gain the special boundary-reflection conditions needed at such frequencies). ${ }^{82}$

This might perhaps accord with PascualLeone's focus-model for the special case of "attention", 62 but there seems no pressing other reason to see them as relevant for practical everyday memory-linking, especially given the complications they would entail, and given the $\{2\}$ alternatives. $^{\mathbf{J}}$

\section{\{5\} Reachable items with the right Name/Label.}

A member-specification which relied on complete descriptions would take us back to intensive definitions, case $\{0\}$, which will often be unworkable. So instead names/labels are used as a shorthand, supposedly representative of the rest of a taton (or at least some common role with others so labelled).

Such labels can then be called upon to ((i), in logic) specify the members thus defined, \&/or ((ii), in microphysiology) to establish virtual links within some part of the Piagetian $\mathrm{M}^{0} \mathrm{~L}-\mathrm{M}^{1} \mathrm{~L}-$ $\mathrm{M}^{2} \mathrm{~L}-\ldots$ hierarchy. And, given the supposed molecular scale, such labels would have to be activated by electromagnetic signals within the IRto-UV range, in a way similar to that depicted in fig.(iv) of ${ }^{85}$ - or, analogously, as has come to be used with a "URL address" on the internet.

Thus their efficient use might free us from any absolute need for dedicated neural-or-telephone pathways (a freedom already well known for the internet). ${ }^{\mathrm{K}}$

\footnotetext{
${ }^{\mathrm{J}}$ Of course such focussed laser beams may well have important roles in cell-division and growth as the history of Gurwitsch's "mitogenic" UPEs attests; but that's arguably a separate issue.

K Meanwhile note that such matching phone-numbers or "labels" are TIME-based "lock-and-key" arrangements analogous to the SPACE-based codes well-known to immunologists and bacteriologists - already discussed above in $\$ 4.4$. This might help our understanding of DNA organisation. One might also (C) R.R.Traill, 2019
} 
Anyhow, one can imagine variations on this URL theme, invoking lists of "link-names" which may (i) be mere repetitions, (ii) items otherwise apparently unrelated, or (iii) near-repetitions for similar items: e.g. in fig. 1 , the " $\alpha-\beta_{1}-\beta_{2}-\beta_{3}$ " could represent a taton at level $\mathrm{M}^{1} \mathrm{~L}$ which derives its significance through its link to nearly-identical tatons (a1 .., a2 .., and a3... - a very-small "choir" perhaps, with names a1, a2, a3).

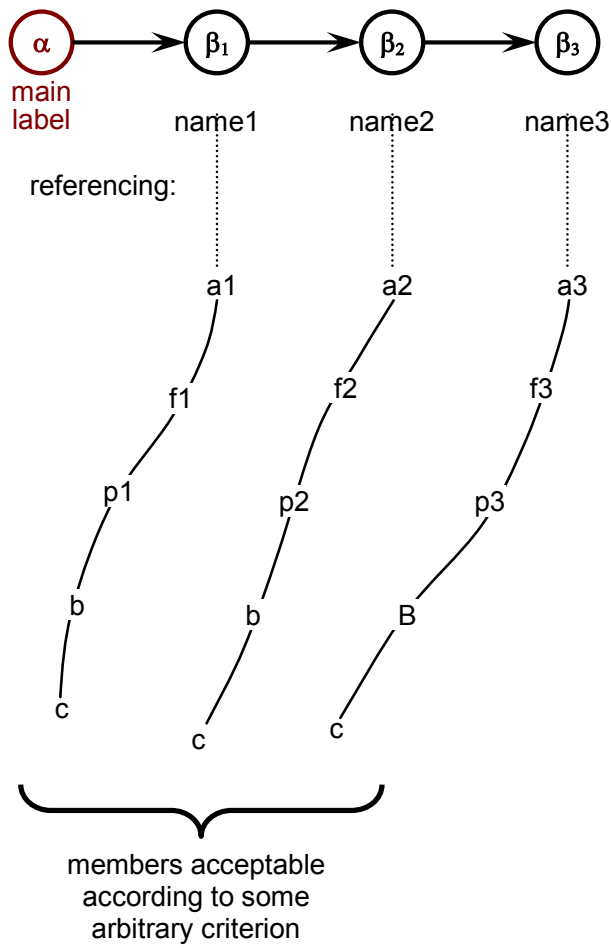

Fig.1 depicting the postulated "higher level" linear element $\left(\alpha-\beta_{1}-\beta_{2}-\ldots\right)$ serving to construct, physically, an extensively defined set or list of "lower" elements. (Abridged from fig.C5.2/3 of ${ }^{88}$ )

\section{\{6\} Orphaned Tatons, and Tenuous Memory}

First consider short-term-memory (STM). Any such coding left unlinked, is likely to be left out of system activities, until it simply "times-out" naturally and disappears unnoticed.

In contrast, any long-term-memory (LTM) which seems to lack current links will (i) have time on its side, and (ii) doubtless have some surviving historical linkages (however faint and remote), since otherwise it is unlikely to have reached longterm status. Nevertheless such memories can become more-or-less isolated, as in "What was that person's name?! — I do know it but..." — and indeed one will usually remember eventually

enquire whether such analogy has any evolutionary significance. (regaining some relevant linkages). Can we explain that?

Some relevant activity might include:

(i) periodic scanning (perhaps random, and perhaps various brain-regions at different times) inciting apparently dormant schémata to renew an old contact or two (via mechanisms considered in $\S 6.3$, below). Or (ii) such specific contacts might occasionally arise spontaneously unprompted. Or (iii), regardless of previous contacts, such "orphans" might have some means of "advertising" their characteristics.

In any case, it may seem to be necessary that they take some initiative on their own, and not just wait for some central controller to call on them unilaterally. (This being in the spirit of Kant's "back-to-front causality" discussed above in $\S 3.1(\mathrm{~K} 3)$, or Piaget's Action First).

\{7\} Any other defining-or-linking strategy that we have overlooked, and which we may find later on. Nature's task seems formidable here, so it will not be surprising if it uses all the feasible tricks available - perhaps often concurrently or as hybrids. Indeed, if we think carefully about officework procedures, most of them do involve hybrid techniques for re-locating records, or items, or staff.

The actual details of such technicalities are not crucial at this stage (especially as we are not sure of their identity, so better variants might be found); but the important point is that any attempt to assemble material-embodiments of mental $\mathrm{M}^{0} \mathrm{~L}-\mathrm{M}^{1} \mathrm{~L}-\mathrm{M}^{2} \mathrm{~L}-$ $\mathrm{M}^{3} \mathrm{~L}$... hierarchies (as implied by Piaget or Ashby) will be faced with $\bullet$ the task of keeping such subunits linked in some way; and we will probably - need all or most of the above tactics - both within the office and in ordered brain-intelligence. - Both being cases of DualPlus (see $\S 4.2$, above).

So if we are serious about Piagetian substructural model-building of the human mind/brain, we need to offer specific plausible material ways to link its tatons into schèmes (by whatever means), thence into new $\mathrm{M}^{0} \mathrm{~L}$-schémata ${ }^{\mathrm{L}}$ - and then (separately) into the $\mathrm{M}^{1} \mathrm{~L}, \mathrm{M}^{2} \mathrm{~L}, \ldots$ schéma-clusters which they must presumably form, in real or virtual space. Some suggested details for additional development were offered in ${ }^{86(\text { chs. } 1,2,6)}$ - invoking list-like linkages to lower levels], and developed further in ${ }^{88(\S C 5.2)}$

At the lowest levels, taton-interaction is likely to be essentially CHEMICAL (type- $\{1\}$ : i.e. quasi-

\footnotetext{
${ }^{\mathrm{L}}$ Then keeping company with any old inherited $\mathrm{M}^{0} \mathrm{~L}$-schémata. (c) R.R.Traill, 2019
} 
contact, or subject to attractive forces, as with hydrogen bonding). But what then?

A little further up the hierarchy, any such directcontact " $\{1\}$ " arrangements, left on their own, would probably soon become unworkable due to overcrowding. - And any alternative lowfrequency WIRE-LIKE LINKAGES ( $\{2 b\}$, usually assumed to adapt via slowish Hebbian procedures $)^{29}$ would seem barely workable for fast-moving multifaceted thought processes, ${ }^{\mathbf{M}}$ though they do seem well suited to revising nerve-layout (as Hebb ${ }^{29}$ suggested, but now with a change in its supposed significance - from actual memory-coding, to signal-channelling).

Meanwhile physical tethering $\{2 a\}$, if it exists in this context at all, would perhaps have a rather specialised use which would probably not concern us here. So let us leave it aside as merely "in reserve".

Higher in the hierarchy there would probably be a need for high-frequency (optical) coding of callsigns (names, labels) as in $\{5\}$ and $\{6\}$, discussed above - along with constraints within "boxlike" enclosures $\{3\}$; which takes us to:

\subsection{Cells as Possible Schéma-Files}

Boxes, bags, and jail-cells are obvious ways of keeping members of a "set" together - and so are their biological equivalents: bio-cells etc., though it is too early to say with any certainty what aspects (if any) of the Piagetian hierarchy are consolidated in this way.

Moreover there is then the question of whether a cell might contain a single "choir-group" of one particular schéma, or whether it might contain various different (but presumably-related) schémata.

Then again, cortical cells are usually held in narrow columns, ${ }^{\mathbf{5 8}}$ and such columns might also be seen as somewhat bigger "boxes" to loosely imprison those particular whole-cells (each with its own imprisoned content of schèmes and schémata or whatever).

Seen that way, we have the possible basis for a hierarchical organisational filing-structure (here at its more-inclusive categories, using $\{3\}$ 's boxes), whereas the most-specific categories would be embodied by quasi-chemical contact $\{1-2 \mathrm{a}\}$ by the memory-entities within the cell - or whatever the smallest $\{3\}$-"prison" might be. Indeed that prompts a more recent thought about smaller boxes:-

\footnotetext{
${ }^{\mathrm{M}}$ Ashby had no such mechanical-linkage problem because he used recursive pre-made electrical devices, or just plain recursive mathematical theory. Anyhow he did not seriously tackle abstract thought except in vague principle.
}

\subsection{Possible Role for virus-sized containers}

As just implied, a neuron-cell might well have the space to house a whole family-or-tribe of related schémata, but new evidence now offers much smaller subfiles within the cell - "granules" $\left(2004^{36}\right)^{\mathbf{N}}$ - later identified as hollow (viruslike ${ }^{42,99}$ ) icosahedral capsids made of Arc-protein (similar to the viral $\mathrm{Gag}$-protein) ${ }^{15,63,14,98}$ "boxes" of about $125 \mathrm{~nm}$ diameter. In principle then, these might offer the first fence-like constraint (type $\{3\})-$ after $\{1\}$ and perhaps $\{2\}$ have exhausted their capabilities.

The above authors and their immediate audience see the purpose of the capsids as "to shuttle information between cells: a new form of cellular communication that may be the key to long-term memory formation and other neurological functions. These vesicles circulate throughout the body, but little is known about their function." "74 that has useful implications which can be taken further (with modification), see $\$ 7$ below.

In contrast, the present argument has hitherto emphasised a rather static classificatory role for any such "jail-like" enclosures - a way of contributing a post- $\{2\}$ practical stage to the structural “...M ${ }^{1} \mathrm{~L}$ $M^{2}$ L-M ${ }^{3} \mathrm{~L}-. . . "$ Piagetian hierarchy. However the two interpretations are probably mutually compatible - and another minor example of the DualPlus principle.

Nevertheless we may need to distinguish capsids according to the cargo that they happen to be carrying.

The official line suggests that they "also move genetic material between cells" ${ }^{, 74}$ (in the form of $m R N A$ \&/or protein); whereas the present paper suggests $\boldsymbol{n} \boldsymbol{c}$ RNA (specifically tatons) and at least some elaborations thereof, (i.e. schèmes \&/or schémata - either singly, or as "choirs" with complementary action-codings). On present indications, both cargo-types seem plausible according to circumstance, ${ }^{\mathbf{O}}$ though the supposed

\footnotetext{
$\mathrm{N}$ “...RNA is transported as large granules, but little is known about them." — " 200 nm in diameter..." - Kanai et al (2004). ${ }^{36} \quad$ Incidentally note that David Glanzman of UCLA (on YouTube and radio) implicates the cell nucleus as the repository of molecular memory; - a similar idea which adds to the possibilities.

$\mathrm{O}$ "Arc capsids encapsulate both the Arc protein (maybe other proteins too?), its mRNA, and whatever mRNA [or tatRNA?] happened to be in the vicinity at the time of encapsulation. Arc capsids are able to protect the mRNA from RNAases." (Neuronicus 2018) $^{\mathbf{5 2}}$ — This latter point (protection from RNAases) might also help explain long-term memory as RNAcoding, without necessarily invoking conversion to DNA to gain the required stability).
} 
ncRNA-taton-cargo has not yet been considered experimentally.

\subsection{Could these items fit in? - "Tape-measure" evidence}

How big are schèmes and schémata likely to be? Could they (or their ensembles) fit comfortably into capsids - or at least into neurons? This calls for some rough, order-of-magnitude calculations.

\subsubsection{Volume of single taton if $<200 b$}

I have hitherto taken a single taton to be a fairly simple "text" of RNA coding, so let us provisionally assume this will usually be a sequence of "short" ncRNAs: - "snRNA" $(<200 b)$. The DNA version has a length ${ }^{43}$ of about $0.34 \mathrm{~nm}$ per bp (base-pair) a total of up to $68 \mathrm{~nm}$, and it has a cross-section of about $3 \mathrm{~nm}^{2}$ - hence a volume of about $204 \mathrm{~nm}^{3}$ but a bit less for single-stranded RNA. So let us provisionally say that a taton is approximately $160 \mathrm{~nm}^{3}$ in volume.

\subsubsection{Volume: schème (as 20 short-taton "choir")}

If a schème is a choir-like ensemble of closelysimilar tatons, then we need to guess the likely size of such a "choir" (ironing out individual discrepancies). Perhaps 20 members would suffice, especially as this whole subsystem might be duplicated elsewhere. ${ }^{\mathrm{P}}$ That would take the volume up to $3200 \mathrm{~nm}^{3}$.

\subsubsection{Volume: schème (choir of longish-tatons)}

Of course if a typical taton is actually LncRNA (not just 200b, but perhaps $1700 \mathrm{~b}$ long, like $m \mathrm{RNA}$, or a more modest $1000 \mathrm{~b}$ for "Other lncRNA") ${ }^{\mathbf{6 0}}$, then the volume of the 20 member schème-ensemble would be significantly greater: $27,200 \mathrm{~nm}^{3}$ — or the

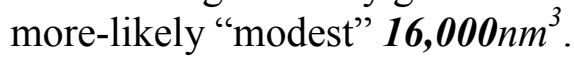

\subsubsection{Volume: whole schéma of longish-tatons}

With all schème-components being "Other LncRNA", then the whole schéma volume could be

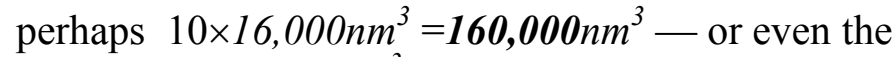
immodest 272,000 $\mathrm{nm}^{3}$.-

Of course these are all just rough estimates to help clarify the possibilities.

\subsubsection{Internal volume for a capsid}

The external diameter of the analogous herpesvirus capsid is " $125 \mathrm{~nm}$ ", 99 and perusal of images

\footnotetext{
${ }^{\mathrm{P}}$ There is likely to be such choir-like redundancy at every $\mathrm{M}^{\mathrm{m}} \mathrm{L}$ level - not just the $\mathrm{M}^{0} \mathrm{~L}$ considered here. So any given schéma is likely be reinforced by other near-duplicates.
}

suggests that $60 \%$ of that diameter is internal, hence $75 \mathrm{~nm}$, and hence an inner radius of $371 / 2 \mathrm{~nm}$, giving

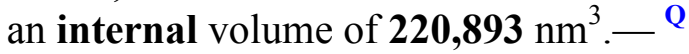

That means that a capsid probably does have enough volume to contain a whole schéma complete with its constituent schèmes and their tatons including reasonable provision for "choir-member" redundancy. However the threshold is narrow enough for the issue to be debatable regarding whole schémata - while clearly having adequate volumes for the less-demanding isolated schèmes $(16,000$ to $27,200 \mathrm{~nm}^{3}$ within the capsid's $220,893 \mathrm{~nm}^{3}$.)

\subsubsection{Internal volume for a cell-body}

Neuronal cell-bodies have diameters ranging from about $7 \mu \mathrm{m}$ to $30 \mu \mathrm{m}$ (at least for inhibitory neurons, ${ }^{4}$ and that seems near enough for all cases considered here). So taking the smallest neuronbody, it will have a volume of about $179.6 \mu^{3}$ i.e. just under $18 \times 10^{\mathbf{1 0}} \mathrm{nm}^{3}$ - enough room to hold (close-packed) nearly $18 \times 10^{4}$ capsids (each $\left.\approx 10^{6} \mathrm{~nm}^{3}\right){ }^{\mathrm{Q}}$ And of course this provides ample space in each separate cell, for a substantial Piagetian mental construct if it is embodied in the way outlined here - even if individual capsids cannot contain constructs larger than a schème. Indeed maybe schémata need the extra ample free-development space amongst-and-between the cell's capsids rather than within those capsids - or perhaps that applies only to higher level schémata $\left(\mathrm{M}^{1} \mathrm{~L}, \mathrm{M}^{2} \mathrm{~L}, \mathrm{M}^{3} \mathrm{~L} \ldots\right)$, rather than the basic $\mathrm{M}^{0} \mathrm{~L}$.

\subsection{Conducting a link between distant sites?}

The current tacit assumption seems to be that messages (of unknown format ${ }^{\mathbf{R}}$ ) are sent along the mysteriously- "correct" nerve-path. Also the destination site will somehow "know" when-andhow to act autonomously or else just obey meanwhile somehow knowing how to use the right unidirectional "phone-line" to communicate back to the sender, or to other relevant sites.

Clearly that summary implies the need for comprehensive clarification, and more reverse engineering if possible.

Note firstly that, for a brain of any complexity, it is simply not possible to run a separate dedicated

\footnotetext{
Q — since sphere-volume $=(4 / 3) \pi r^{3} . \quad$ Meanwhile the external volume would be $1,022,653 \mathrm{~nm}^{3}$ - about $10^{6} \mathrm{~nm}^{3}$

${ }^{\mathrm{R}}$ Of course it is also mostly assumed that AP signals carry the main brain-messages, whereas the view here is that electromagnetic signals (EM: infra-red IR, visual, or UV) play this main role - at least as far as 1D logical thought is concerned.
} 
"phone line" between each pair of participating sites. (The required number escalates out of control; - and even if this were possible, that would not help much unless there were some means for choosing which line to use.)

The other extreme would be to broadcast the same current message universally to all sites, all the time - and that too would soon produce an unworkable system - a cacophony of jumbled messages, mostly irrelevant to any given recipient.

Countries and other large social organisations have very similar dilemmas:- (They too are all "epistemological machines," each seeking to cope with a similar nearly-insolvable problem which is arguably formally equivalent in each case - despite outward appearances; see $\$ 4.4$ above). Anyhow, this gives us some provisional license to draw on analogies, and consider, e.g., how a large office (or even a nation) manages its information - though I will comment on only some features here.

Firstly, it needs a fairly-sophisticated and rapid (alphabet-or-phoneme-based) SYSTEM OF LANGUAGE - not just a system of "volume-controls" (no matter how detailed) as the AP system seems to be. Within society, with some overlap, this comes mainly as $(\alpha)$ written symbols, $\& /$ or $(\beta)$ acoustic wave structures; - \&/or, since Marconi: $(\gamma)$ speech or code via electromagnetic (EM) wave-structures, including $(\gamma 1)$ coaxial and other cables, as from about the $1850 \mathrm{~s}$; - plus $(\gamma 2)$ radio, microwave, and infra-red (IR) - and now especially the multitude of short-range gigabit devices, notably using WiFi techniques for making-and-maintaining wireless connections through heterogeneous changing domains. $^{57}$

Here we are looking for speed-capability, (which is perhaps peripheral in $\alpha$ 's case), but the other two are indeed fast - especially $\gamma$. So can we think of any other such fast external-transmission methods for society? Until we do, let us provisionally assume that $(\alpha)-\beta-\gamma$ is the full list, and look for corresponding (necessary?) analogues within the brain:

$\alpha$. Taton-codings or schèmes appear as "written symbols" (letters, phonemes or words etc., depending on the $\mathrm{M}^{0} \mathrm{~L}-\mathrm{M}^{1} \mathrm{~L}-\mathrm{M}^{2} \mathrm{~L}-\ldots$ level), with schémata acting as sentences or concepts) — as discussed above from a quasi-static point of view. $\beta$. Acoustic internal signals seem less important here, and can thus be bypassed in our immediate discussion. ${ }^{\text {s }}$ However:-

1. Compact-myelin axons (via PLP protein) offer efficient coaxial connections, as discussed above in $(\S 1(1-2)$, and $\S 2.2(\mathrm{~d}, \mathrm{e}, \mathrm{h})$ - a definite parallel to technology if we accept this apparent EMrole within biology; and

$\gamma$ 2. EM can offer radio-like wireless breakaways from the cable-system $\S 2.2(f, h, i, j)$. In principle this means that any two sites within the brain might be able to intercommunicate even without myelin (lipid) connections provided that there were an intervening "atmosphere-equivalent" which was sufficiently transparent for the main frequency in question! In practice, unaided, that would seldom be the case except at short range (e.g. $<20 \mu \mathrm{m}$, or somewhat further-apart when the IR frequencies are closer to red-light-, etc.); but some assistance from WiFi-like adjustments, and from cables for most of the journey might often suffice. In that case, it would clearly be helpful if the AP system could (as classically suggested) keep upgrading the cablepathways according to apparent need - using the well-known Hebbian principles of growth according to actual usage. ${ }^{29}$

This idea that EM signals need not be confined to specific cables within the brain, may also help to explain a strange difference between the central and peripheral nervous systems (CNS and PNS):

In the PNS, myelin is provided by Schwann cells, each of which serves only one axon; whereas in the CNS myelin comes from oligodendrocytes, each of which serves many axons - which might well tend to allow "crosstalk" leakage from one serviced-axon to another. - But that would hardly matter if CNS fibre-transmission is just an aid to address-coded broadcasting in comparatively indiscriminate directions. Against that, peripheral nerves are presumably mainly concerned with traditional AP input and output signals, which $d o$ need to avoid crosstalk between dedicated links.

\subsection{Attention-"centre" and the flow of concepts}

Provisionally at least, it seems appropriate to postulate the existence of an attention-centre deemed to be in temporary close-contact with whatever schémata are currently in play.

It can hardly be at any single point or microentity. Rather it must probably be some ensemble of privileged schémata or suchlike. Such entities are

\footnotetext{
S (Acoustic excitons are arguably involved in playing the role of AP-analogues taking a trigger-impulse along a taton's linear RNA-structure).
} 
likely to be physically close to each other - though not necessarily so if communications are adequate. The nature of such links can be provisionally assumed to be similar to other intra-brain links (see $\S 6.3$ below), but privileged in some way, e.g. by proximity or pre-set dedicated lines.

The two-lobed thalamus offers some scope for plausible sites (\&/or the prefrontal cortex with which it is in close contact); while the hippocampus seems not to, (see the discourse in $\S 7.1$ below, regarding "patient HM" with bilateral hippocampusdestruction). But for present purposes, the actual location of the "attention centre" is not vital to our discussion provided that some adequate internallinkage is usually assured.

(It may be of some incidental relevance to note the famous apparently limited capacity of such attention centres:- about 7 items simultaneously at any one time $\left(\text { G.A.Miller, 1956) }{ }^{\mathbf{5 0}}\right)^{\mathrm{T}}{ }^{\mathrm{T}}$

\section{Message-interactions}

\subsection{Message "programs"}

Regarding coded action-programs, $\S 4.5$ above offered the likely basic taton format as:

$\left[\begin{array}{l|l|l}\hline \text { Label } & \text { Switches } & \text { Program }\end{array}\right]$

Here the Label+Switches together act to filter out all supposed irrelevancies, so the taton will only act when stimulated with the right lock-combination. But what about the actual "Program"? What can it actually do at the micro level such that it will achieve its more-macro Piagetian action-component? It was presumed it would first need to coordinate with its fellow "choir" members, using cross-feed signals; but what next for this collective schème action?

At the basic Piagetian Sensori-Motor level $\left(\mathbf{M}^{0} \mathbf{L}\right)$, its expected action will depend on whether it is "sensori" (input), or "motor" (output) in its nature.

If sensory, it will presumably send a suitable code to the relevant part of the thalamus (or suchlike) to be analysed as part of the overall input appraisal.

\footnotetext{
T Some more-modern opinions (varying Miller's "7") have been offered in J.Pascual-Leone et al.(2015) ${ }^{62}$, invoking increasing values of his own metric "M" from $M=1$ (at 1-month) to $M=6$ (at 2-years), and $M=13$ (at adulthood). - Also he suggests that $\mathrm{M}$ at least partly determines the Piagetian cognitive stage; and, influenced by R.Case, he has revised the boundaries and names of those four Piagetian stages to Sensori-motor (1m$18 \mathrm{~m}$ ), Inter-relational (up to $5 \mathrm{yrs}$ ), Dimensional (to 11), and Vectorial (to 19).
}

If motor, we would expect it to participate in causing some muscle to contract-or-release - or a whole pattern of such muscle-responses if we are considering the combined program for a whole schéma. If such programs can indeed be fully coded within individual neuron bodies (as suggested above in §5.4), then they are ideally situated to launch EM signals into the end of the associated narrow myelin cable. $^{\mathbf{U}}$

For other Piagetian levels $\left(\mathbf{M}^{1} \mathbf{L}, \mathbf{M}^{2} \mathbf{L}, \mathbf{M}^{3} \mathbf{L} . ..\right)$ it will be a bit different - with contacts for $\mathrm{M}^{\mathrm{m}} \mathrm{L}$ schémata now being usually with $\mathrm{M}^{\mathrm{m}-1} \mathrm{~L}$ entities in the level below, (or indeed with partners at the same $\mathrm{M}^{\mathrm{m}} \mathrm{L}$ level) - but deep within the brain proper, thus having no direct access to the outside world. Fig.1 ( p.9) suggests these two types of link, but says nothing much about the technicalities of linking sites which are not actually touching, (only suggesting vaguely "seek and ye shall find" — "mode $\{0\} "$ in §5.1)). Yet these distant links must become more important as the " $m$ "-level increases, enabling increasing levels of mental-abstraction. So how could such sometimes-lengthy links occur in material terms?

The usual loose assumption is that direct predetermined nerve connection is the answer (once it has been installed) — case $\{2 \mathrm{~b}\}$ in $\S 5.1$ above. That is clearly part of the solution, though it leaves some details unexplained. ${ }^{69}$ However, for our present purposes we can simply accept such partiallyadequate cables as given infrastructure, and seek further possible mechanisms (with a tentative expectation that they will be EM-compatible):-

(To make this discussion easier, it seems helpful to revive the word "schemoids" "schèmes" and "schémata" collectively — though many authors (e.g. Phillips ${ }^{65}$ ) simply use the two

U This stricture would perhaps solve a technical problem:Practical coaxial cables need to be somewhat narrower than the half-wavelengths of their intended signal-traffic, to suppress any tendency for these signals to bounce side-to-side in a zigzag pattern (causing delay, dispersion, and hence distortion) leaving only the straightforward "TEM" mode, parallel to the axis, which is theoretically unhindered by narrowness.

A new practical trouble is that it can be difficult to steer EM signals through such narrow aperture-holes (which is how we are protected from microwave ovens by the fine-holed screening of their windows). However the placing of the radiation source close-and-central (i.e. within the cell-body at one end of the axon) may well overcome the difficulty in this neuron/myelin case.

Incidentally, that constraint would also mean that EM signals would nearly always travel in the same within-axon direction as the APs - orthodromically, away from the cell-body. 
words indiscriminately anyhow, as intimated above in $\S 3.2(\mathrm{JP} 1 \mathrm{a})$.)

\subsection{Uniting sometimes-remote schemoids}

The point is that the more complex schémata are here deemed to be constructed from an assortment of "lower" schemoids." And (as discussed in §5.1) the nature of the necessary structural links can be expected to vary in nature and distance from $\{1\}$ physical contact, through $\{2\}$ tethered-locally, $\{3 a\}$ "imprisoned" in capsids, or then to $\{3 b\}$ "fenced in" within the much larger neuron-cellbodies.

That repertoire might suffice to explain macroschéma cohesion in many cases, but sometimes it will be important to include a link to some remotelylocated schemoid (e.g. some vital hereditary schemoid) which is not locally available. What then? That takes us to feasible-option $\{5\}$ : the use of coded "labels, addresses, URLs, phone-numbers" which can be used to establish-and-maintain highlyselective contact, despite distance.

That dependence on labels, takes us back to fig.1 (and indeed to the in-text sketch repeated at the start of this section). It is also a more refined equivalent to $\{0\}$ 's "seek and ye shall find"- improved because we can expect it to be easier to find tidy labels than whatever complex entities are attached to them.

Note too, as implied earlier, that here we have a TIME-BASED lock-and-key coding (like a combination-lock), whereas the lock-and-key mechanism for immunology and embryology etc. uses solid 3D keys of shaped-protein: $X, Y, Z$-BASED. Thus, at least for the hereditary cases, both types of lock-code could even appear side-by-side on the DNA - the one leading to taton-ncRNA, and the other to mRNA - analogous perhaps to verbs and nouns respectively!

This all depicts a quasi-static macro-schéma perhaps encoding some skill, but open to improvement. This could come through rehearsal which might have at least two different effects:

(i) encouraging local substitutes-for (or copies ${ }^{\mathrm{W}}$ of) any remotely linked components, to make the arrangement faster and more efficient; (ii) replicating (if possible), to add redundancy, as part of the choir-effect at this level (in addition to its

\footnotetext{
${ }^{\mathrm{V}}$ Such a schemoid hierarchy is formally similar to nested subroutines in machine-language computer-programming.

${ }^{\mathrm{w}}$ Copies - perhaps imported physically from that distant site! Maybe unlikely here, but this transport-tactic seems probable elsewhere (as we shall see below in $§ 7$ ).
}

development at other levels). Both could be expected to improve performance.

But the topic of "performance" takes us to another role for distant EM linkages:

\subsection{Activating remote schemoids}

Moving now from quasi-static structure, to dynamic activity (though there is arguably a fuzzy distinction between them):

Whatever their groupings or locations, schemoids are there to dynamically influence each other during thinking and other mental activity. And it has been argued here that the only fast and potentially-accurate way to convey that influence within the brain-proper is by EM signals such as IR (with the traditional AP signals playing an important-but-secondary dynamic-infrastructure role). Moreover coded labels seem indispensible here, to achieve the necessary selectivity.

In essence then, these "talk" linkages are seen as closely similar to those offered above for holding the quasi-static states together - only here the case for using "addressed" messages is rather more obvious. In both cases it is difficult to see how a selforganising system like the body-and-brain could survive without such well targeted time-based messaging (just as they also need well targeted 3Dbased physical linkages).

Until now, we all seem to have tacitly assumed that any transmitting site will somehow "know" which nerve-fibre to consign the message onto (and that every likely destination will have its own dedicated line, which is a further problem). But how will it know? OK it may well have an address-code, but will it then recognise the relevant "phone-line" for that address. If most of our human society members can now be selectively contacted by mobilephone (without any dedicated cable-link), then why not consider that nature might be doing much the same within the brain?

Yes, in both environments there is a need for general-purpose cables-or-whatever to bridge the gap when long-distances are involved. (Hence the need for major nerve tracts within the brain, such as the corpus callosum connecting the left and right hemispheres.) No doubt some lines might be dedicated - in the optic nerve perhaps (though that has been questioned ${ }^{84 \text { :foot-27 }}$ ) — but such dedicated private lines are arguably not the general rule.

There is still the problem of knowing the "phone-number" of the recipient (even if the traditionally-assumed choice of dedicated lines were 
to apply $\left.{ }^{\mathbf{x}}\right)$. In the case of essential inherited linkneeds, it seems likely that the call-code is already pre-ordained. But for learned contacts, this code may well come from (Darwinian) trial-and-error perhaps assisted by many candidate-destinations, each emitting an occasional "I'm here" signal (with its "return address") to advertise its presence.

For the specialised apparently-pixellated transmission of $2 D$ images, ${ }^{\mathbf{Y}}$ any pixel-address codings would probably derive from a systematic formula - which could actually then serve mainly for the pioneer fibres when they link up the solid connections for each dedicated pixel-line of the set — "docking" correctly.

\subsection{Finding little-used schémata: Dim memories}

As described so far, the important schemoids would all be (or soon become) readily accessible via (i) the conveniently placed network of the main myelinated nerve-fibres - updated by Hebbian ${ }^{29}$ principles favouring those frequently used; and (ii) the ability of EM signals to travel freely for shortish distances without cable assistance.

Also note (iii), that it should usually be easier to access the larger target offered by a collective macro-schéma consisting of many "choir" members (e.g. spread across several cells). - The extra size being achieved typically through repeated rehearsal.

But, coming back to daily life, what about that name, word or detail which you thought had permanently entered your long-term memory (LTM), but you now have great trouble recalling? Like "Wallerian degeneration," that could be because its disuse had allowed Hebbian procedures ${ }^{29}$ to overlook decay-or-obsolescence of the cable access to your sought-for vicinity, whilst boosting other regions.

You might then remember the half-forgotten name in due course (at the whim of autonomous activity), but that might depend on the sought-for schéma emitting the afore-mentioned occasional "I'm here" advertisement, presumably with its return address or other "branding" to assist access.

\footnotetext{
$\mathrm{x}$ i.e. Even if we were to fully accept the traditional AP model for coping with an incoming signal, there would still be the problem of: "How would the system "know" which of the available non-random paths or actions to take. E.g. could the message specify "Option X"? And if so, then how would it recognise that option? - By "Name X" or what?'

${ }^{Y}$ Separate from the other parallel visual coding system, using vector linkages as advocated by Piaget and by Pylyshyn. See $\S 1 .(8)$ above, where both-in-cooperation are deemed necessary (and exhibiting the spirit of DualPlus).
}

\subsection{Fading schémata in the hippocampus}

For short-term memory (STM) there is the more pressing issue of actual schéma-decay - perhaps by $20 \%$-per-day of schéma-X's choir-population until there is nothing but a mere trace (if that) of it left in the hippocampus, with no guarantee of recoverability. That leads to a separate major issue in the next section, but first we need to clarify some terminology (which sometimes varies between authors):

"STM" is usually taken to include both "IMMEDIATE MEMORY" (gone after about a secondor-less unless rehearsed), and "WORKING MEMORY" (which may last a day or so, even weeks with some rehearsal or active usage). Here it seems useful to introduce the abbreviations "imM" and "wkM" respectively for these two types of memory - both still distinct from LTM.

\section{Memory-Migration to Cortex}

\subsection{Patient-HM with no hippocampus nor "wkM"}

The well-known account by Scoville and Milner $(1957)^{76}$ reports on three patients (HM, DC and MB) whose hippocampus had been largely obliterated bilaterally, and were no longer capable of holding wkM, nor of sending any new memories to the cortex as LTM - though they could recall material which had been stored in LTM before the operation. (The symptoms were essentially the same in each case, but HM is the one most discussed).

That clearly implicates the hippocampus as the key locale for (declarative) $\mathbf{~ w k M ~ - ~ w i t h ~ H M ~ e t c ~}$ unable to remember even what the last topic was during the previous minute, nor any other detail of the post-operation past.

However it is easy to overlook his ability to use im $M$ in his immediate present. (Obviously any patients who could not, would hardly be in a fit state to be interviewed!) The importance of this is that it means that there must be a third domain for this extra memory mode - though we can probably identify it (abstractly) as being the "attention centre" as discussed above in $\S 5.6$ (and $\S 6.1$ ).

Plausibly then, such attention-centre activity was going on while HM was being interviewed. But note that he would meanwhile have to be accessing (i) his pre-surgery memories stored in his cortex (prefrontal or otherwise) - and (ii) the perhaps-numerous "housekeeping" hereditary schémata (wherever they happen to be stored). So there would have been significant trans-cranial fast-messaging, just to interact coherently in the "here and now" but with no need (in this task) for the destroyed hippocampus. 


\subsection{Properties of the imM (Immediate Memory)?}

This apparently-necessary "here-and-now" feature (distinct from wkM) seems somewhat overlooked. So it may be helpful just to jot down some likely aspects:

This imM must be very dependent on new tatons acquired "just-now" - presumably acquired as partly described above in $\S 4.7$. This might include editing ${ }^{91}$ of any suitable pre-existing tatons, either by similar Darwinian trial-and-error or maybe (due to the special circumstances) by purpose-built "quickrecording" tactics.

Attention is called for here (whether conscious or not), so it seems reasonable to expect the main site of such activity to be within some sort of "attention centre" - whatever that might be, and wherever it is located.

For present purposes it is not vital to identify the location of the attention-centre, except that it is not in the hippocampus (at least not in HM's case). Nevertheless it is convenient to provisionally assume that it is within the thalamus, and indeed circumstantial evidence rather supports that view:

Various parts of the thalamus clearly sort and then integrate various sensory signals. Notably: (1) Auditory signals (via cochlear, olivary complex and inferior colliculus) go to the medial geniculate nuclei of the THALAMUS - then sent on to the cortex. Meanwhile (2) Visual signals take at least three different paths [a] $\approx 2 \%$ to the hypothalamus (as a light-meter), but then [b] some to the THALAMUS's lateral geniculate; while [c] some (via the superior colliculus) to the THALAMUS's pulvinar - both then linking to the occipital lobe at the rear of the cortex (which then projects to $\bullet$ a dorsal parietal path, or - a ventral temporal-lobe path. ${ }^{41:(\operatorname{chs} .9-10)}$ And most other senses also have a similar thalamic involvement.

Be that as it may; let us now return to the issue of MEMORY AND HOW IT MAY PROGRESS through the above-mentioned three domains: Attention-centre for imM,

Hippocampus (if available!) for wkM, and Cortex for LTM. — And let us start with this (into-Cortex) last step, as it is better documented:

\subsection{From Hippocampal wkM to Cortical LTM?}

7.3.1 Here we provisionally assume that the relevant memories are already encoded within the hippocampus, held for temporary use but ready to be either forgotten as obsolete, or transferred to LTM.

In traditional AP theory, such coding (if considered at all) has been taken to be somehow embodied in either (i) reverberating AP neural circuits, \&/or (ii) some feature of the synaptic connections.

In both cases, there seem to be formidable problems if such encodings of compound-structure are to be re-located. They could perhaps $\{\alpha\}$ be translated back into virtual experience, and transmitted via AP messages such that the LTM could reconstruct them on a smaller scale - though that would seem to be unnecessarily inefficient and subject to gross error.

$\{\beta\}$ Alternatively, like moving an entire house, whole synaptic/AP structures could conceivably be relocated physically - along with some way of restoring the external links by changing to new dedicated nerve-fibres (like changing one's address, plus landline-connection and its phone-number; etc.). That might be possible, but again it seems unnecessarily difficult, and indeed improbable enough to make one doubt the whole transfer enterprise.

Fig.2. Principal neural connections relating to intelligence. Note that, due to feedback loops etc., the neat sequence shown here is only a rough guide in tracing causality.

Cerebral Cortex (with LTM)

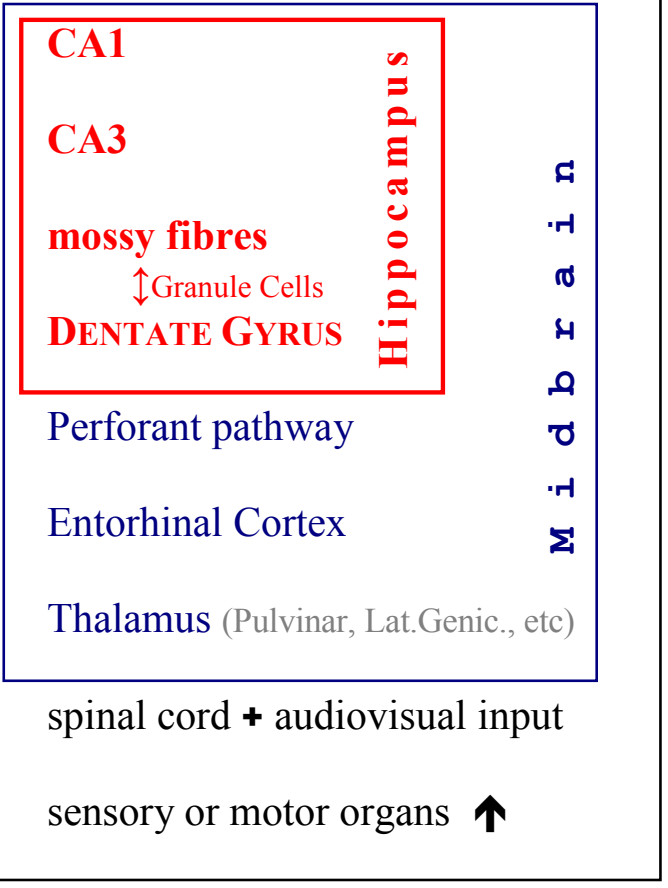

7.3.2 Looking instead at the EM/schemoid theory, the $\{\alpha$-(now micro) $\}$ virtual-re-enactment case still looks inconveniently complicated with its required reconstruction, but at least it does have the benefit of invoking EM signals with their vastly greater gigabit broadband - much more suitable for carrying complex instructions. 
But with $\{\beta$-(micro) $\}$ "house-moving" we arguably do have a workable system: The coding is taken to be held by molecular-based schémata either as free-floating pseudo-molecules, or grouped into capsids, \&/or already held within dedicated cells (which seems to tally with the account offered by Deng et al $(2010)^{\mathbf{1 6}}$ regarding mice.) - These new neurons-or-capsids would all be comparatively easy to transport as intact semi-nomad entities.

Moreover, their links to distant archive sites (cortical or otherwise) are presumed to be more like WiFi than the conventional landline connections so they would effectively have "mobile-phone" connection, not seriously disrupted by reasonable moves if adequate routers- $\& /$ or-cables were available.

\subsubsection{Any Evidence for such a Schéma-flow?}

There is indeed evidence for a flow of new neurons from the hippocampus to the cerebral cortex, even in adulthood. And such mobile neurons might well be carrying updated schémata. However the issue is currently in serious dispute in the case of humans (see $\$ 7.3 .5$ below).

The old doctrine was that there was absolutely no further increase-or-replacement of neuron numbers once an individual reached adulthood.

Nottebohm $\left(1981^{53}, 1984^{54}, 1985^{55}\right)$ demonstrated that this was not true - at least in the canary, which apparently discarded its song-memory neurons at the end of the season, and then developed new ones later. Nottebohm $(2002)^{\mathbf{5 6}}$ attributed this phenomenon to a need to abandon obsolete memory which might otherwise prevent new LTM acquisitions. That could be correct, though there is also a variation on this idea:- That, for bird-flight, weight is at such a premium that surplus semi-junk needs to be discarded even if it must be re-acquired later. ${ }^{91\{\S(14)\}}$

Meanwhile there seems to be no evidence that such pre-programmed culling of LTM occurs in normal human cases - but do we actually gain any neurons? Rodents and many other vertebrates apparently do continue supplying new neurons into adulthood, (conveyed from the hippocampus to the cerebral cortex), but this adult-supply seems absent in humans and dolphins — as discussed in §7.3.5 below. But first let us look at how this transportation works, in-so-far as evidence is available, especially in infancy and earlier:-

\subsubsection{Observed flow of Neurons into the Cortex}

Let us initially leave aside the contentious question of adult migration, and look at pre-adult developments. It turns out that none of the cortical neurons develop on-site.(Rakic, 2007) ${ }^{73}$ I.e., they have all migrated, and he also reports that this idea was put forward by Wilhelm His in $1874^{30}$ and $1904^{31}$

Rakic's investigations $1975^{71,} 1985^{72}$ and reported on Rakic $2007^{73}$; Cowan $1979^{12(p 63)}$ showed that radial string-like glial cells served to guide the migrating neurons out of "the subgranular zone" (SGZ) of the Dentate Gyrus (DG) - though the "the subventricular zone" (SVZ) might also be involved.

Other treatments of this question of cell-migration are reported by Fuster (2003) ${ }^{\mathbf{1 9}}$, Tan et al $(2013)^{81}$, Sekine et al $(2014)^{77}$, Oyarce et al $(2014)^{59}$, plus Mayer \& Fishell (2018) ${ }^{48}$.

Moreover some have endorsed the Nottebohm notion of this migration persisting into adulthood in at least some mammals: Gage (2002) ${ }^{\mathbf{2 1}}$, Zhao, Deng \& Gage (2008) ${ }^{\mathbf{1 0 0}}$, Ming \& Song (2011) ${ }^{\mathbf{5 1}}$, Hayashi et al $(2015)^{27}$, Gonçalves, Schafer \& Gage $(2016)^{23}$.

\subsubsection{Migration-failure in Primates and Dolphins?}

However Rakic himself (2007) ${ }^{73}$ had also noted a surprising conclusion that this neuron-flow to the cortex ceased in primates "without addition or turnover throughout life" and concluded that this "may be a critical step in the evolution that allows of mental prowess in Homo sapiens" ... with "a permanent population of cortical neurons [which] may be more valuable for survival of primates".

Later, more specific human studies, tracing the increasing failure during the transition to adulthood were reported simultaneously by Sorrells et al $(2018)^{78}$, and by Weiler $(2018)^{97}$ — followed by a report which also noted this failure in dolphins: Parolisi et al (2018) ${ }^{61}$.

\subsubsection{Interpretation and Possible-Solutions?}

Maybe the flow of neurons, where it exists, is indeed no more than an initial-stockup or replenishment, as Nottebohm (2002) $)^{56}$ and Rakic (2007) ${ }^{73}$ suggest. - Maybe. - But ongoing memory is SOMEHOW conveyed from the Hippocampus to LTM in the Cortex, and the flow of any cells does rather look like a required mail-delivery (especially when it seems that cells-as-boxes may already be important for that other reason of defining schéma-ensembles; see $§ 5.2-\S 5.4$ above). Hence the neuron-migration in rodents and (most?) other mammals does make sense - but that "sense" breaks down for primates, so what are we to make of it?

If evolutionary nature persists with a change which seems counter-productive, then there are likely to be cogent hidden reasons. In this case such 
reasons could be (1) need for more constancy in LTM, as Rakic suggested, or (2) some better method has evolved - and we might wonder what new facility primate brains have to offer which might promote such better methods.

One relevant asset may be the availability of higher meta-levels for schéma-organisation: $\mathrm{M}^{2} \mathrm{~L}$, and (in humans) $\mathrm{M}^{3} \mathrm{~L}$. It is not clear what difference this could make, but it might make possible more sophisticated coding such as would make broadband EM instructions more feasible, thus superseding the "mail" service by a "broadband online" arrangement. (In practice, that does not work well for very-large data-sets on the internet - where it is actually more efficient to record them onto a USB memory-stick, and mail it in the old-fashioned way). However maybe human complexities are such that LTM cannot cope with a mail-delivered onslaught, as Rakic implies.

As a variation of that idea, more sophisticated mechanisms could perhaps be assembled in the prefrontal cortex during infancy - mechanisms with a useful repertoire of promising local schémata, such that they could be invoked from afar with comparatively minimal instructions, thus making the other (high throughput) arrangements superfluous. (Maybe such developments would depend on $\mathrm{M}^{\text {high }} \mathrm{L}$ facilities).

However we can imagine that this could impose a certain stereotyped element into the mental world of adults - and some might say that this is "all too true"! Likewise it might be significant that adults find it more difficult to pick up a second or third language.

Another possibility is a flow of migrating loosecapsids (instead of cells), though it is far from clear how they could manage the journey. Presumably they would be ill-equipped to climb up the radial glia-strands in the way that mobile-neurons do but it might we worth checking.

If no such method seems valid, then we had better keep looking for another solution, because adult humans surely do keep forming long-term memories, by one means or another!

\subsection{Immediate-Memory to hippocampal wkM?}

This is the preceding step, deferred earlier for relative lack of information, and that lack still applies. If necessary we might invoke the second step $(\S 7.3)$ as a perhaps useful analogue.

However the problem seems simpler than that. Indeed the troublesome matter of major-transmission might easily be bypassed by supposing the hippo- campus has enough independence to do some of the input-interpretation directly itself, without waiting for every report from the attention-centre. After all they are primarily operating simultaneously on the same real-time events - which of course fits with our using the term "STM" to include both.

Meanwhile it may still be possible to continue the reverse-engineering process embarked on earlier - but perhaps some additional clear data may be required first.

\section{ACKNOWLEDGEMENT}

I wish to thank Sherrill Hallmond for useful discussion and suggestions.

\section{References}

1 Abbott, E.A. (1884 / 1952). Flatland. Penguin

2 Ashby, W. R. (1952/1960). Design for a Brain. Chapman \& Hall: London.

3 Bannister Don. (1968). "The Myth of Physiological Psychology" Bulletin of the British Psychological Society, 21, 229-231.

4 Beebe NL, JW Young, JG Mellott, \& BR Schofeld (2016 Apr 6) "Extracellular molecular markers and Soma size of inhibitory neurons: Evidence for four subtypes of GABAergic cells in the inferior colliculus" J.Neuroscience 36(14), 3988-3999.

5 Bishop, G.H. (1956). "Natural history of the nerve impulse". Physiol. Rev., 36, 376-399.

6 Brette, R. (2017 Jul. 27 first posted online) "Is coding a relevant metaphor for the brain?" bioRxiv doi: http://dx.doi.org/10.1101/168237.

7 Briggs JA, Wolvetang EJ, Mattick JS, \& Barry G. (2015 Dec). "Mechanisms of Long Non-coding RNAs in Mammalian Nervous System Development, Plasticity, Disease, and Evolution". Neuron 88(5), 861-877.

8 Burnett, F.McF. (1957) "A Modification of Jerne's Theory of Antibody Production using the concept of Clonal Selection", Austr. J. Sci., 20(3), 67-69.

9 Burnett, F.McF. (1959), The Clonal Selection Theory of acquired immunity, Cambridge University Press.

10 Cifra M, \& P Pospíśil (2014) Ultra-weak photon emission from biological samples: definition, mechanisms, properties, detection and applications. Journal of Photochemistry and Photobiology B: Biology. 139: 2-10.

11 Cifra M, C.Brouder, M.Nerudová \& O.Kučera (2015 Feb 25) "Biophotons, coherence and photocount statistics: a critical review". arXiv: 1502.07316v1

12 Cowan WM (1979 Sep) "The Development of the Brain" Chapter-V in The Brain, Sci.Amer:Libr ; pp 56-69.

13 Crick FHC (1979 Sep) "Thinking about the Brain" Chapter-IX in The Brain, Sci.Amer:Libr ; pp 130-137.

14 Dai X \& ZH Zhou (2018 Apr 6) "Structure of the herpes simplex virus 1 capsid with associated tegument protein complexes" Science 360(6384)

15 Day C \& JD.Shepherd (2015Jul.1) "Arc: building a bridge from viruses to memory" Biochem.J, 469(1): e1-3.

16 Deng, W., J.B.Aimone, and F.H. Gage (2010 May). New neurons and new memories: how does adult hippocampal neurogenesis affect learning and memory? Nature Reviews Neuroscience. 11(5): 339-350. 
17 Dinger MF, Mercer TR \& Mattick JS (2008 Apr) "RNAs as extracellular signaling molecules." J.Mol.Endocrinol., 40(4): 151-9.

18 Fodor, J.A. (2008; prev.1975). The Language of Thought Revisited. Oxford University Press.

19 Fuster, J.M. (2003). Cortex and Mind: unifying cognition, Oxford University Press.

20 Fuster, J.M. \& Bressler S.L. (2012 Apr,(Epub:Mar 20)) “Cognit activation: a mechanism enabling temporal integration in working memory." Trends Cogn Sci. ;16(4): 207-18. doi: $10.1016 /$ j.tics.2012.03.005.

21 Gage FH (2002) "Neurogenesis in adult brain?" J. Neuroscience, 22(3), 612-613

22 Gallistel CR \& PD Balsam (2014 Feb) "Time to rethink the neural mechanisms of learning and memory" Neurobiol.Learn.Mem. 108, 136-144.

23 Gonçalves JT, ST Schafer \& FH Gage (2016 Nov 3). "Adult neurogenesis in the hippocampus: From stem cells to behavior". Cell 167, 897-914. 180501-1520

24 Gurwitsch, A. (1924a) „Physikalisches über mitogenetische Strahlen“. Archiv für Entwicklungsmechanik, 103: 490-498.

25 Gurwitsch, A. (1924b). Les problèmes de la mitose et les rayons mitogénétiques. Bull. d. Histol. Appl.,1: 486

26 Hardwick SA et 10 al.+ Martin A Smith, \& JS Mattick (2019 Feb 4). "Targeted, high-resolution RNA sequencing of noncoding genomic regions associated with neuropsychiatric functions" bioRxiv.

27 Hayashi et al (2015) Hayashi K, K-I Kubo \& K.Nakajima (2015 Apr). "Cellular dynamics of neuronal migration in the hippocampus" Frontiers in Neuroscience. 9 , article:135. ${ }^{\prime} 180501-1715$

28 Heaviside O. (1894/1970) Electrical Papers (mainly vol.2). Macmillan.

29 Hebb, D.O. (1949/1964). The Organization of Behaviour. Wiley: New York \& London

30 His, W. (1874) Unsere Körperform und das physiologisch Problem ihrer Entstellung: Briefe an einen befreundeten.

31 His, W. (1904) Die Entwicklung des monschlichen Gehirns wahren der ersten Monate. Leipzig, Hirzel

32 Horgan John (2016, Mar. 22) The Singularity and the Neural Code. Sci.Amer.: Cross-Check Blog.

33 Hydén, H. (1967b). "Biochemical changes accompanying learning”. In G.C.Quarton, T.Melnachuk, and F.O.Schmitt (eds), The Neurosciences, pp.765-771, 913, 914. Rockefeller University Press.

34 Jerne, H.K. (1955) "Natural-selection Theory of Antibody formation" PNAS, 41 (11): 849-857. doi:10.1073/pnas.41.11.849.

35 Jerne, H.K. (1966) "Antibody formation and immunological memory" In Gaito, J. (1966a) Macromolecules and Behavior. Meredith/Appleton-Century-Crofts: New York; Ch.9, pp151157

36 Kanai Y, N.Dohmae \& N.Hirokawa. (2004) “ Kinesin transports RNA: isolation and characterization of an RNA-transporting granule". Neuron, 43(4): 513-525

37 Kant, I. (1787/1855) (Transl. JMD.Meiklejohn, from $2^{\text {nd }}$ edition) Kritik der reinen Vernunft / Critique of Pure Reason. Dent: London.

38 Kant, I. and Jonathan Bennett (2007/2017) [paraphrase with commentary, of]: Critique of Pure Reason up to the end of the Analytic.

https://www.earlymoderntexts.com/assets/pdfs/kant1781part1.pdf

39 Knowles, L. (2017 Feb 22) :’The evolution of myelin: Theories and application to human disease" J. Evolutionary Medicine. 5, art.235996. doi: $10.4303 / \mathrm{jem} / 235996$

40 Koch, Christof \& G.Marcus (2014 June 17). "Cracking the brain's codes." MIT Technology Review, 117(4), 42-46. https://nyuscholars.nyu.edu/en/publications/cracking-the-brains-codes

41 Kolb B, IQ.Whishaw,\&GC.Teskey $\left(5^{\text {th }}\right.$ edn) "An introduction to Brain \& Behavior" Worth:NY

42 Lalonde ,MS \& WI.Sundquist (2012 Nov 13) "How HIV finds the door" PNAS, 109(46): 18631-18632.
43 Lehninger, Albert L (1975, $2^{\text {nd }}$ ed). Biochemistry: the molecular basis of cell structure and function. Worth Publishers.

44 Mattick, J.S. (2001). "Noncoding RNAs: the architects of eukaryotic complexity". EMBO Reports 2(11), 986-991. http://emboreports.npgjournals.com/cgi/content/full/2/11/986

45 Mattick, J.S. (2003). "Challenging the dogma: The hidden layer of non-protein-coding RNAs on complex organisms" Bioessays. 25, 930-939. www.imb-jena.de/jcb/journal club/mattick2003.pdf

46 Mattick, J.S. (2004 Oct). "The hidden genetic program of complex organisms" Scientific American. 291(4), 30-37.

47 Mattick, J.S. (2018 Aug 10) "The State of Long Non-Coding RNA Biology" Non-Coding RNA, 4, 17-28.

48 Mayer Ch, \& G.Fishell (2018 Aug 2). "Nascent neurons need nature and nurture" [neurodevel.] Nature 560, 39-40.

49 Mehler MF \& Mattick JS (2007 Jul. 1) "Non-protein-coding RNAs and RNA editing in brain development, functional diversification and neurological disease." Physiol. Rev. 87, 799-823.

50 Miller, G.A. (1956). "The magical number seven, plus-or-minus two: some limits on our capacity for processing information". Psychological Review, 63(2), 81-97.

51 Ming GI \& H.Song (2011 May 26). "Adult neurogenesis in the Mammalian Brain: Significant Answers and Significant Questions." Neuron, 70, 687-702.

52 Neuronicus (2018) in The Science Portal: https://scientiaportal.wordpress.com/2018/01/28/interview-with-jasond-shepherd-phd/

53 Nottebohm, F. (1981) “A brain for all seasons: Cyclical anatomical changes in song control nuclei of the canary brain" Science, 214(4527), 1368-1370.

54 Nottebohm, F. (1984) Birdsong as a model in which to study brain processes related to learning. Condor 86:227-236.

55 Nottebohm, F. (1985) "Neuronal replacement in adulthood." in: Hope for a new neurology. Ann NY Acad Sci 457: 143-161.

56 Nottebohm, F. (2002 Feb 1) "Why are some neurons replaced in adult brain?" J.of Neuroscience, 22(3), 624-628. http://psych.colorado.edu/ munakata/csh/nottebohm.pdf

57 O’Sullivan, J.D., G.R.Daniels, T.M.P.Percival, D.I.Ostry, \& D.Eastwood (1996, Jan.23). Wireless LAN [Local Area Network]. US Patent Number 5487069. [Assignee: CSIRO].

58 Opris I. (2014 July) "Prefrontal cortical minicolumn: from executive control to disrupted cognitive processing" Brain, 137(7), 1863-1875.

59 Oyarce K, ER Bongarzone, \& F.Nualart (2014 Mar). "Unconventional Neurogenic Niches and Neurogenesis Modulation by Vitamins" J.Stem Cell Res. Ther.,4(3): 184-206.

60 Palazzo AF \& ES.Lee (2015 Jan 26) "Non-coding RNA: what is functional and what is junk?" Frontiers in Genetics 6, e2.

61 Parolisi R, B.Cozzi \& L.Bonfanti (2018 Jul.20) "Humans and Dolphins: Decline and Fall of Adult Neurogenesis" Frontiers in Neuroscience.

62 Pascual-Leone, J. \& A., and M.Arsalidou (2015 July). 'Neuropsychology still needs to model organismic processes "from within".' Behavioral and Brain Sciences, 38. DOI: $10.1017 / \mathrm{S} 0140525 \mathrm{X} 14000983$

63 Pastuzyn ED, CE.Day,+10+JD.Shepherd (2018 Jan.11) "The neuronal gene Arc encode a repurposed retrotransposon Gag protein that mediates intercellular RNA transfer" Cell. 172(1-2): 275-288.e18.

64 Pauling, L. (1960/1967). The Nature of the Chemical Bond. Cornell University Press.

65 Phillips, J.L.jr (1969). The Origins of Intellect: Piaget's Theory. W.H.Freeman: San Francisco.

66 Piaget, J. (1927/1930) La causalité physique chez l'enfant The Child's Conception of Physical Causality. Routledge \& Kegan Paul

67 Piaget, J. et al. (1946/69) Le développment de la notion de temps chez l'enfant - The Child's Conception of Time. R\&KP.

68 Piaget, J. and B.Inhelder (1948/1956/1963/1967). The Child's Conception of Space. Routledge \& Kegan Paul: London. 
69 Pollard, T.D. (2015 Dec 21). "New light on growth cone navigation" Developmental Cell, 35, 672-673.

70 Popper, K.R. (1975/1994) "The rationality of scientific revolutions"; (i) in Rom Harré (ed.) (1975) Problems of Scientific Revolution. Scientific Progress and Obstacles to Progress in the Sciences, The Herbert Spencer Lectures 1973. Clarendon Press: Oxford.

71 Rakic P.(1975) "Cell migration and neural ectopias in the brain" [conference] in: D.Bergma (ed,1982!) Birth Defects: Original Article Series. 11(7): 95-129.

72 Rakic P (1985). "Limits of neurogenesis in primates". Science, 227,154-156. [PubMed: 3291 116]

73 Rakic P (2007). "The radial edifice of cortical architecture: From neuronal silhouettes to genetic engineering." Brain Res. Rev. 55(2), 204-219.

74 Reardon S (2018 Jan 11) "Cells hack virus-like protein to communicate" Nature News

75 Rose, S.P.R.(2015 Feb 14) "50 years of neuroscience". Lancet, 385(9968), 598-9.

76 Scoville, W.B., \& B.Milner. (1957). Loss of recent memory after bilateral hippocampal lesions. Journal of Neurology, Neurosurgery and Psychiatry. 20, 11-21.

77 Sekine, K.; Ken Ichiro Kubo; and Kazunori Nakajima (2014 Sep) "How does Reelin control neuronal migration and layer formation in the developing mammalian neocortex?" Neurosci. Res., 86: 50-58. [Epub 2014 Jun 23]

78 Sorrells SF, Paredes MF et 16 al +Arturo Alvarez-Buylla (2018 Mar 15). "Human hippocampal neurogenesis drops sharply in children to undetectable levels in adults." Nature 555, 377-381.

79 Squire LR, \& ER.Kandel (1999). Memory: from mind to molecules. Scientific American Library: New York.

80 Sun Yan, Chao Wang, \& Jiapei Dai (2010, Jan). "Biophotons as neural communication signals demonstrated by in situ biophoton autography". Photochem. Photobiol. Sci., 9, 315-322

81 Tan X, \& Shi S-H, (2013 Jul 2). "Neocortical neurogenesis and neuronal migration" Wiley Interdisciplinary Reviews: Developmental Biology 2(4):443-59. doi 10.1002/wdev.88

82 Thar, R., and Kühl,M. (2004). "Propagation of Electromagnetic radiation in mitochondria?". J. Theoretical Biology, 230(2), 261-270. http://www.mbl.ku.dk/MKuhl/pages/PDF/Thar\&Kuhl2004.pdf

83 Thomson, W. [Lord Kelvin] \& G.G.Stokes (1855). "On the theory of the electric telegraph". Proceedings of the Royal Society, 7, 382-399.

84 Traill, R.R. (1975feb/2007apr). Thinking as mental modelbuilding: a Piagetian-cum-mechanistic explanation of the 'engram'. Monograph 12, Institute of Cybernetics, Brunel University. [ www.ondwelle.com/OSM04.pdf + https://bura.brunel.ac.uk/handle/2438/725/1/BrMon12b.pdf ]

85 Traill, R.R. (1976a /2007). The gulf between behavioural psychology and fundamental physiology: a systematic attempt to bridge the gap. Monograph 15, Institute of Cybernetics, Brunel University. (www.ondwelle.com/OSM05.pdf)
86 Traill, R.R. (1976c /2007c:oct). Short papers and letters on the 'linear micro-element' theory of mental mechanism; and related questions of scientific method. Ondwelle Publications Monograph 18, Cybernetics, Brunel University. https://bura.brunel.ac.uk/handle/2438/727/1/BrMon18h.pdf . or www.ondwelle.com/OSM06.pdf

87 Traill, R.R. (1978a) Kybernetes; (1978a) Analytical Theory of Sensori-Motor Spatial Development. Kybernetes, 7, 61-71.

88 Traill, R.R. (1978b/2006). Molecular explanation for intelligence..., Thesis, Brunel University; ( in 2 files: Part-B + all other parts) https://bura.brunel.ac.uk/handle/2438/729

89 Traill, R.R. (1988). "The case that mammalian intelligence is based on sub-molecular memory coding and fibre-optic capabilities of myelinated nerve axons". Speculations in Science and Technology. 11(3), 173-181.www.ondwelle.com/OSM10en.pdf

90 Traill, R.R. (1999). Mind and Micro-Mechanism: a hunt for the missing theory. Ondwelle: Melbourne www.ondwelle.com/BK0_MU6.PDF ISBN: 0-9577737-0-6 (p.bck)

91 Traill, R.R. (2008a/2005b). Thinking by Molecule, Synapse, or both? - From Piaget's schema, to the Selecting/Editing of $n c R N A$. Ondwelle. www.ondwelle.com/OSM02.pdf [French version: www.ondwelle.com/FrSM02.pdf] - Both also in Gen.Sci.J.

92 Traill, R.R. (2010a). Meaningful UV and IR photon-exchange within bio-tissue? - Interdisciplinary evidence, and a new way to view asbestos toxicity. Ondwelle: Melbourne. www.ondwelle.com/UV1 evidence.pdf

93 Traill,R.R. (2011a) "Coherent Infra-Red as logically necessary to explain Piagetian psychology and neuro-microanatomy Two independent corroborations for Gurwitsch's findings, and the importance of self-consistent theory". J.Physics: Conference Series, 329, 012018. doi:10.1088/1742-6596/329/1/012018 http://iopscience.iop.org/1742-6596/329/1/012018

94 Traill, R.R. (2015) Concurrent roles for the eye (Passive 'camera' plus active decoder) - Hence separate mechanisms? Ondwelle: Melbourne www.ondwelle.com/VisionTheories.pdf

95 Trettenbrein PC (2016) "The demise of the synapse as the locus of memory: a looming paradigm shift?" Frontiers in Systems Neuroscience

96 van Wijk, R. \& van Wijk EPA (2005) "An introduction to human biophoton emission" Forschende Komplementärmedizin und Klassische Klassische Naturheilkunde 12, 77-83.

97 Weiler N., (2018 Mar). "Birth of new neurons in the human hippocampus ends in childhood: - Adult 'neurogenesis,' observed in other species, appears not to occur in humans." Science Daily.

98 Yong Ed (2018 Jan 12) "Brain cells share information with virus-like capsules" The Atlantic

99 Yuan Sh. et 11 al (2018 Apr 6) "Cryo-EM structure of a herpesvirus capsid at 3.1 А̊” Science 360(6384) (p48)

100 Zhao Ch, W.Deng \& F.H.Gage (2008 Feb 22) "Mechanisms and functional implications of Adult Neurogenesis". Cell 132, 645680. 